NIST Technical Note 2137

\title{
Quantifying Operational Resilience Benefits of the Smart Grid
}

Cheyney O'Fallon

Avi Gopstein

This publication is available free of charge from: https://doi.org/10.6028/NIST.TN.2137

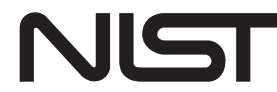

National Institute of Standards and Technology

U.S. Department of Commerce 
NIST Technical Note 2137

\title{
Quantifying Operational Resilience Benefits of the Smart Grid
}

\author{
Cheyney O'Fallon \\ Avi Gopstein \\ Smart Grid and Cyber-Physical Systems Program Office \\ Engineering Laboratory
}

This publication is available free of charge from: https://doi.org/10.6028/NIST.TN.2137

February 2021

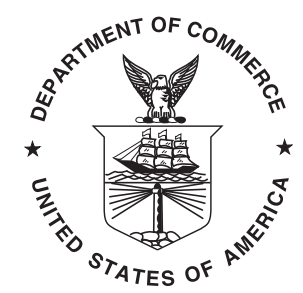

U.S. Department of Commerce Wynn Coggins, Acting Secretary

National Institute of Standards and Technology James K. Olthoff, Performing the Non-Exclusive Functions and Duties of the Under Secretary of Commerce for Standards and Technology \& Director, National Institute of Standards and Technology 
Certain commercial entities, equipment, or materials may be identified in this document in order to describe an experimental procedure or concept adequately. Such identification is not intended to imply recommendation or endorsement by the National Institute of Standards and Technology, nor is it intended to imply that the entities, materials, or equipment are necessarily the best available for the purpose.

National Institute of Standards and Technology Technical Note 2137 Natl. Inst. Stand. Technol. Tech. Note 2137, 52 pages (February 2021) CODEN: NTNOEF

This publication is available free of charge from: https://doi.org/10.6028/NIST.TN.2137 


\begin{abstract}
Automated systems for network protection, outage management, and restoration enable electric utilities to maintain service continuity through network reconfiguration. We evaluate the impact of interoperability investments on distribution system resilience during Hurricane Irma through a reduced form analysis of sustained customer outages. The expected number of interruption hours during that hurricane was relatively lower for regions of the Florida distribution grid that invested more in interoperability enhancements, all else being equal. We use advanced metering infrastructure penetration as a proxy and leading indicator of investment in interoperability enhancements. Employing only publicly available data resources, we conservatively estimate that Florida counties that made these investments realized nearly $\$ 1.7$ billion of operational resilience benefits in the form of avoided customer interruption costs during Hurricane Irma.
\end{abstract}

\title{
Key words
}

Hurricane Irma; Interoperability; Resilience; Smart Grid. 


\section{Table of Contents}

1 Introduction 1

2 Data and Literature Review 3

2.1 Interoperability and Advanced Metering 3

2.2 Hurricane Irma 5

2.3 Electric Service Interruptions 9

2.4 Ancillary Data Resources 13

3 Empirical Strategy 13

4 Results $\quad 16$

4.1 Counterfactual Analysis 19

5 Robustness Checks 25

5.1 Alternative Specifications 25

$\begin{array}{lll}5.2 & \text { Nonlinearity } & 28\end{array}$

5.3 Alternative Weather Data 28

5.4 Impact of Weather Station Outages on Counterfactual Estimates 29

5.5 Alternative Interruption Cost Estimates 32

6 Conclusion $\quad 33$

References $\quad 33$

$\begin{array}{ll}\text { Appendix A: Supplemental Materials } & 37\end{array}$

\section{List of Tables}

Table 1 Conditional expectation of customer interruptions 19

Table 2 Actual and counterfactual outcomes 24

Table 3 Comparison of actual and counterfactual outcomes 25

Table 4 Alternative regression model specifications (county-utility) 26

Table 5 Alternative regression model specifications (county) 27

Table 6 ICE calculator results (Actual - $C F_{0}$ ) 32

Table 7 Covariate Balance Table $\quad 38$

Table 8 Quadratic-Quintic Interactions with Wind and AMI-Share (County-Utility) 39

Table 9 Quadratic-Quintic Interactions with Wind and AMI-Share (County) 40

\section{List of Figures}

Fig. 1 Share of customers served by AMI 
Fig. 2 Annual data from FERC Form 1 for FPL with respect to: (a) the value of metering infrastructure, and (b) the value of communications equipment. In each panel the solid line represents the total asset value for the category while the dashed and dotted lines represent the value of new additions and retirements, respectively.

Fig. 3 Weather station outages. (a) The spatial distribution of weather stations and outages, as well as Hurricane Irma's track. (b) The temporal distribution of weather station outages during Hurricane Irma.

Fig. 4 Synthetic wind speed data. (a) Synthetic wind speed data and the percent of accounts interrupted for Palm Beach county Florida in September 2017. (b) Maximum synthetic wind speeds at the county level.

Fig. 5 System average interruption duration index. (a) Map of SAIDI values at the county level. (b) Histogram of SAIDI values for the sample of county-utility pairs.

Fig. 6 Interruption summary. (a) Customer interruption counts for Florida in September 2017. (b) County-level interruption counts at the coincident peak. (c) Percent of accounts interrupted in each county at the coincident peak.

Fig. 7 Graphical representation of core results. (a) The number of interruptions sustained in an hour, decomposed by wind speed and the share of customers served by AMI. (b) The differential in resilience to interruptions exhibited by segments of the grid that had AMI penetrations above and below $50 \%$.

Fig. 8 Observed and modeled sustained interruptions (SI) for: (a) High-interoperability county, and (b) Low-interoperability county.

Fig. 9 Actual and expected performance for counties: (a) ranked by AMI share, and (b) ranked by $\triangle$ SAIDI.

Fig. 10 Performance relative to $C F_{M}$ expectations

Fig. 11 Peak coincident interruptions for: (a) counterfactual $C F_{0}$, (b) counterfactual $C F_{1}$, (c) actual observations.

Fig. 12 Regression results with alternative wind speed metrics 29

Fig. 13 Wind speeds and sustained interruptions in Miami-Dade County 30

Fig. 14 SAIDI Performance and AMI Share 41

Fig. 15 SAIDI Performance and AMI Share $\quad 42$

Fig. 16 Bay and Jackson $\quad 43$

Fig. 17 Orange and Brevard $\quad 44$

Fig. 18 Pinellas and Manatee $\quad 45$ 


\section{Glossary}
AMI Advanced Metering Infrastructure
ARRA American Recovery and Reinvestment Act
EIA Energy Information Administration
FEP Fixed Effects Poisson
FERC Federal Energy Regulatory Commission
FPL Florida Power and Light
IOU Investor Owned Utility
ISD Integrated Surface Dataset
METAR Meteorological Terminal Aviation Routine Weather Reports
SGIG Smart Grid Investment Grants 


\section{Introduction}

In September 2017, Hurricane Irma made landfall and travelled the length of peninsular Florida over several days. The storm brought extreme winds, torrential rains, flooding, and electric service interruptions to an area where tens of millions of Americans live. Over the previous quarter century, utilities and the communities they serve invested billions of dollars towards a more resilient power grid. In the wake of Hurricane Irma, stakeholders understandably ponder how effective these investments have been at mitigating bad outcomes for their communities.

Strong winds and the debris they carry often cause electrical grid outages. Conventional service restoration entails the dispatch of work crews to the site of the problem, a time and labor-intensive process that cannot begin until the safety risk from the storm has diminished. The deployment of smart grid technologies enables utilities to employ new, more autonomous, restoration strategies.

Using automated systems for network protection, outage management, and restoration enables utilities to maintain service continuity through network reconfiguration even as portions of the system fail. As automated responses preempt the need for manual restoration, customer interruptions may shorten from hours or days to fractions of a second. Whereas future hurricanes will continue to cause power outages, advanced distribution technologies deliver value to stakeholders through rapid handling of interruptions that would otherwise be sustained longer.

The boundary between grid reliability and resilience is sometimes unclear, as both are typically assessed by measuring customer interruptions. A simple but meaningful distinction is that sustained interruptions-or those longer than 5 minutes [1]—are reliability events, while the resilience domain encompasses shorter and momentary disruptions [2]. Self-healing grid mechanisms can operate within this five-minute window and create resilience signatures that are distinct from the longer time-frame recovery of manual restoration actions.

Successful hazard mitigation and response strategies in modern electrical grids require synthesis and coordination of information and activity across many individual components. A highly interoperable distribution grid—one where multiple networks, systems, devices, and components can work together and readily exchange information [3] — can quickly assess conditions and dynamically coordinate the optimal response. Interoperability is therefore foundational to the ability of distributed intelligent grid devices to adapt to changing conditions and withstand and rapidly recover from disruptions. These are the fundamental elements of infrastructure resilience [4].

Interoperability in electrical systems is often difficult to assess and typically derives from extensive work at the utility that is not externally visible. However, utility deployments of smart meters and advanced metering infrastructure (AMI) may be a visible leading indicator of interoperability. Integration of AMI with billing systems, customer information systems, outage management systems, and distribution management systems has been shown to improve the AMI value proposition, the overall level of interoperability [5], and 
to have increased the efficiency of the post Hurricane Irma recovery efforts [6]. The most salient proxy for the level of utility interoperability is therefore the share of customers with smart meters within each market segment.

This manuscript presents evidence that regions of the distribution grid with interoperability enhancing investments were relatively more operationally resilient to Hurricane Irma, sustaining fewer customer interruptions than would have otherwise occurred for a given level of wind stress. We employ a reduced form approach to evaluate the impact of interoperability investments on distribution system resilience and the propensity for customers to experience sustained interruptions to their electric service during a major hurricane.

The central empirical strategy employed in this study is difference-in-differences analysis, employing the fixed effects Poisson (FEP) estimator. Hourly datasets of the 67 Florida counties and 206 county-utility pairs are assembled. These datasets contain variables for the number of sustained interruptions present in each segment of the grid (county or countyutility service territory), as well as a metric of the wind speed incident on the local electric grid. The share of customer accounts in each grid segment interconnected through AMI is assumed to be static for the duration of the study period (September 2017). Consequently, a time-invariant AMI-share is absorbed into the county and county-utility level fixed effects along with all unobserved variables that vary by grid segment and not time.

The impact of AMI-share on system outcomes is recovered by interacting AMI-share with a metric for local wind speed to construct a new independent variable for inclusion in the core regression specification. The metric for local wind speed is constructed as a spatially weighted average of observations obtained from surface weather stations located across Florida. Drawing on existing literature [7,8], we employ the square of the local wind speed metric $\left(W^{2}\right)$, as it is roughly proportional to the dynamic pressure exerted by wind. This approach allows for the estimation of the impact of wind speed on the rate at which sustained interruptions accumulated for a given level of wind speed stress and AMI penetration. This approach also allows for comparison of the estimated resilience impacts of AMI penetration with those of other potential influences ranging from building stock characteristics to community socioeconomic factors.

We investigate three counterfactual scenarios to characterize some of the resilience benefits already coming from interoperability improvements and the additional opportunities still available to stakeholders. The first counterfactual $\left(C F_{0}\right)$ addresses the question of what benefits to resilience have already been realized through the deployment of AMI and othe smart grid technologies. With the second counterfactual $\left(C F_{1}\right)$ we assess how much better the system could have performed if additional opportunities were pursued. The third counterfactual $\left(C F_{M}\right)$ estimates the performance of the distribution grid under the assumption of a uniform distribution of AMI penetration at the state-level average.

Using these counterfactuals, we estimate the benefits of interoperability investments to the operational resilience of the Florida grid to entail 112 million fewer customer interruption hours, which is conservatively valued at $\$ 1.7$ billion. Interoperability value propositions are challenging to estimate with empirical rigor, and the examples from which 
stakeholders may draw inference are limited [9-11]. To our knowledge, this manuscript constitutes one of the first such evaluations of the interoperability value proposition within the context of the distribution grid.

The rest of this manuscript is organized as follows. Section 2 presents background information and descriptions of the data used in the study. Section 3 details the empirical strategy. The main results are presented in section 4. Section 5 conducts several checks on the robustness of the core findings, and section 6 concludes with a brief discussion. Additional tables and figures can be found in the supplementary materials available online.

\section{Data and Literature Review}

Analyzing the impact of interoperability investments on electric grid resilience requires data on investments, the stresses to which the grid is subjected, and the outcomes of this stress. All of the data resources employed in this study are publicly available. In some cases, superior data resources may exist. However, some forms of high-quality data on electric grid assets may not be readily available due to business or national security concerns. While a fully specified network model of grid assets, informed by geographic information systems may enable methodological improvements over the present study, the costs of obtaining and appropriately handling such information has indicated the pursuit of a more reduced form approach to estimating the impact of interoperability improvements on system outcomes like operational resilience. This section describes the data we employ, and reviews the literature that informed the choice of that data.

\subsection{Interoperability and Advanced Metering}

Interoperability investments come in many forms and offer diverse benefits and costs to utilities. A common initial step towards enhanced interoperability is the deployment of smart meters to the premises of utility customers. AMI investments enable improvements to the baseline level of interoperability between utilities and their customers. It is through these technological gateways and associated platforms that many utilities hope to improve their service offerings, demonstrate new value propositions, and gain customer support for much needed system investments. AMI investments constitute a class of interoperability enhancement offering improved informational and control channels within the firm deploying the technology. Furthermore, publicly available data can be used for high-level empirical characterization of AMI deployment patterns. AMI deployment is therefore a visible leading indicator of and proxy for investments in interoperability.

The value proposition for investments in AMI is enhanced through its integration with other critical utility systems. The integration of AMI with billing systems, customer information systems, outage management systems, and distribution management systems further improves the overall level of interoperability and the AMI value proposition [5].

The simplest metric for the level of interoperability between a utility and its customer base is the share of customers within each market segment for whom utility transactions 
are facilitated with AMI. For the analysis presented in this paper, AMI proxies for interoperability levels are constructed for each county in Florida.

The Energy Information Administration (EIA) collected advanced metering data on form EIA-861M from 2011 to January 2017. Annual data for 2016 is used to determine the share of utility customers interconnected through AMI at each reporting Florida utility. While meter count data is disaggregated by end-use customer segment (residential, commercial, etc.), spatial disaggregation is only at the state level. Therefore, the distribution of AMI assets within the service territory of a given utility is assumed to be spatially uniform.

The share of customers with AMI and the severity of hurricane induced grid stress varies substantially across the state of Florida. As of the end of 2016, the AMI share of customer accounts ranged from a high of over $99.9 \%$ in Walton county to a low of less than $0.1 \%$. The spatial distribution of AMI is presented in Fig. 1. AMI shares are highest in the urban centers of southeast Florida, the far western panhandle, and the western peninsular coast south of Tampa Bay. A lower share of customers have AMI in much of central Florida.

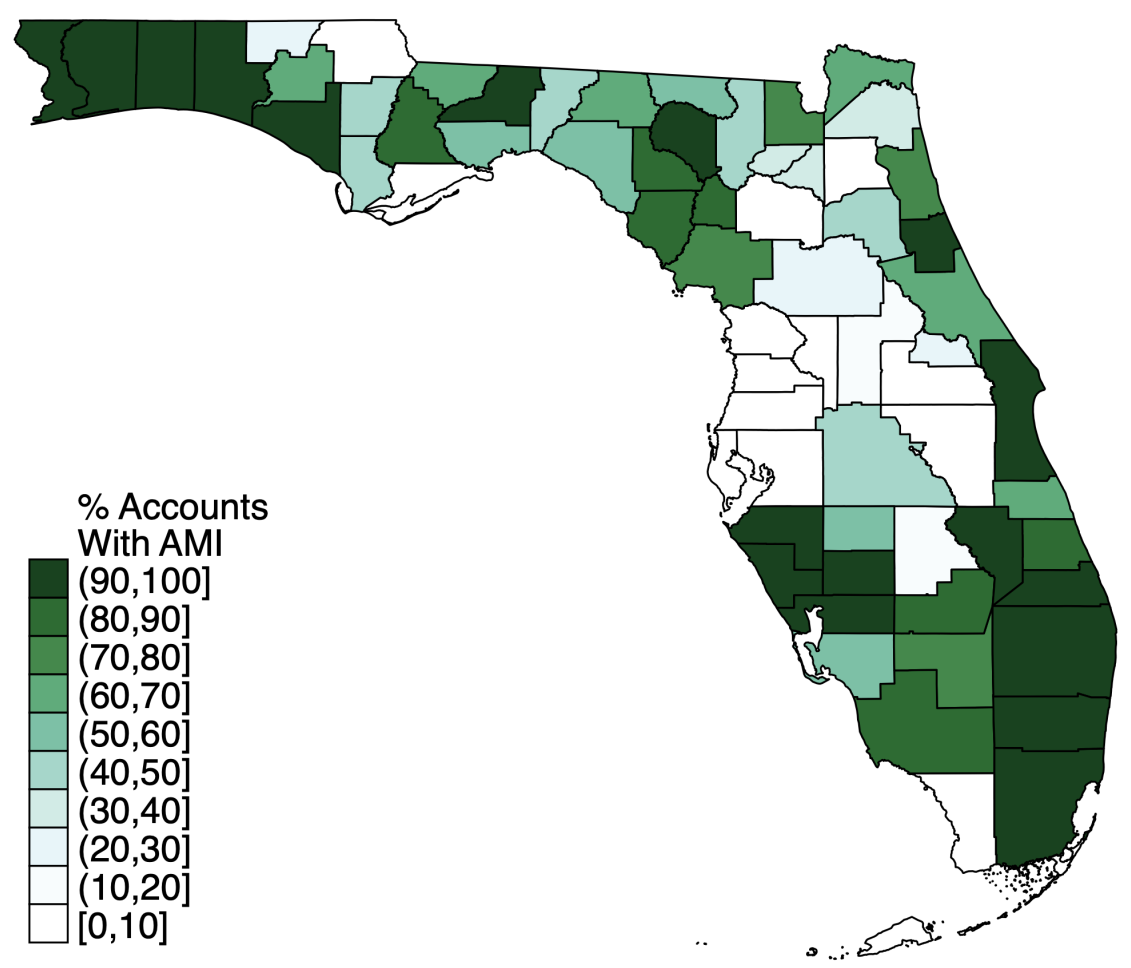

Fig. 1. Share of customers served by AMI

AMI deployments (counts of customers with AMI) are accurately measured in annual reports to the EIA. However, this data is collected at the utility level at a point in time over nine months before Hurricane Irma made landfall in Florida. To obtain county-level and sub-county-level (utility-county-level) estimates of the share of customers interconnected through AMI, distributional assumptions must be made. The measure of AMI-share used 
for each county is a linear combination of AMI-shares and customer counts of each utility operating in the county.

At the organizational level, there is a nearly bimodal distribution of AMI customer shares. That is, most utilities have either deployed AMI to nearly all customers or almost none. Few utilities exhibit an intentionally mixed strategy of AMI and other classes of meters. A number of electric utilities received matching funds for grid improvements from the Smart Grid Investment Grant (SGIG) program as part of the American Recovery and Reinvestment Act (ARRA). These funds increased their ability to achieve full implementation. In Florida, utilities received \$261.6 million from recovery act funding to augment the participant cost share of $\$ 446.1$ million [12]. ${ }^{1}$

A review of Federal Energy Regulatory Commission (FERC) Form 1 filings for investor owned utilities (IOU) in Florida produces evidence of the build out of metering infrastructure. Fig. 2a shows that Florida Power and Light (FPL), the largest IOU in the state of Florida, increased the rate of investment in metering infrastructure in 2010.

Fig. $2 \mathrm{~b}$ presents evidence that investments in metering infrastructure coincided with the 2010 inflection point in communications equipment investment made by FPL. It is interesting to note that the nearly monotonic increase in metering infrastructure value is not echoed by the communications investment series, where several cycles of addition and retirement of equipment can be seen in the disclosure data. While disclosure data is excellent for understanding long-term trends, its further inclusion in this study is precluded by its lack of spatial disaggregation with respect to key investment variables and its coverage of only four IOU in Florida.

Current FERC record keeping does not disaggregate switching devices from other overhead line equipment in annual asset value reports. Thus, the public record does not contain explicit evidence of the investments that firms have made in automated protective devices.

\subsection{Hurricane Irma}

Florida is a strong candidate for the study of electric grid interoperability and resilience due to the size of its economy and population, the level of exposure to grid stress in the form of severe weather events, and the technological sophistication of its utilities. The peninsular geography of Florida means that the state can only import and export electricity along its northern boundary. For the most part, contingencies must be handled locally.

The National Hurricane Center found that, "Irma caused widespread devastation across the affected areas and was one of the strongest and costliest hurricanes on record in the Atlantic basin" [13]. An estimate of damages from Hurricane Irma arrived at a value of uninsured and insured losses among residential and commercial properties of between $\$$ 42.5 billion and $\$ 65$ billion [14]. Cangialosi et al. [13] reports the storm attained its

${ }^{1}$ Florida Power and Light (FPL), serving more customers than any other Florida electric utility, undertook the largest SGIG project. Energy Smart Florida had a total project value of \$ 579 million, and entailed the installation of 2.6 million smart meters, 9000 intelligent distribution devices, 45 phasors, and monitoring equipment in more than 270 substations [12]. 


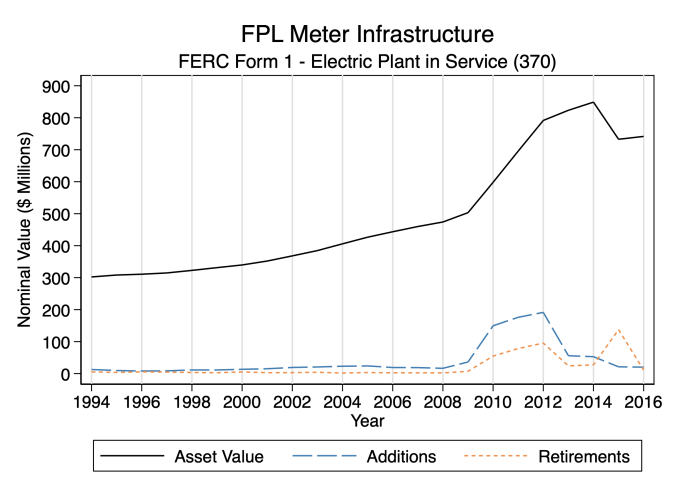

(a) Investments in metering infrastructure by FPL

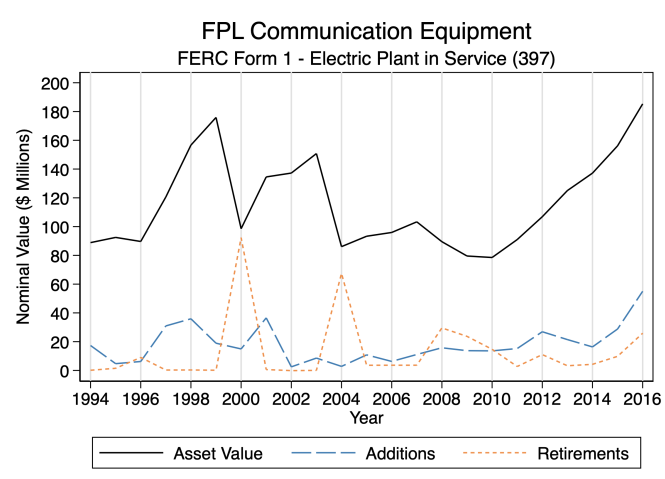

(b) Investments in communications equipment by FPL

Fig. 2. Annual data from FERC Form 1 for FPL with respect to: (a) the value of metering infrastructure, and (b) the value of communications equipment. In each panel the solid line represents the total asset value for the category while the dashed and dotted lines represent the value of new additions and retirements, respectively.

maximum wind speeds of 80 meters per second $(178 \mathrm{mph})$ the evening of September $5^{\text {th }}$ and made landfall in Barbuda the following morning as a category 5 hurricane with a minimum pressure of 91400 pascals $(914 \mathrm{mb})$. Arriving with 58 meter per second $(130 \mathrm{mph}$ ) wind gusts, Hurricane Irma made landfall in Florida on September $10^{\text {th }}, 2017$ [15]. After arriving on the Florida mainland as a category 4 hurricane, Irma proceeded to traverse the length of the state's western coast.

While Irma was especially forceful, the severity of its impact on Florida is demonstrative of past electric grid experiences with hurricanes. In reviewing data originally presented by Hines et al. [16], Wang et al. [17] reports that between 1984 and 2006, hurricanes and tropical storms accounted for $4.2 \%$ of large blackouts in the United States, with the second largest mean size in MW (1309), and largest mean size in customers (782 695) of any hazard. For coastal communities, especially those along the southern and eastern seaboard, hurricanes represent an anticipated threat to local and regional economic activity against which improved resilience is a clear goal.

Hurricane Irma caused interruptions for 6.7 million customer accounts in Florida, a state with 10.5 million accounts across all end use sectors at that time. The recovery effort was massive, involving over 50000 recovery workers from around the United States and Canada. The Florida Public Service Commission collected data from 47 of the 49 utilities that accepted mutual aid in restoration efforts. The reporting utilities employed 27628 crews, under 248 managers, requiring 1.69 million meals and incurring 103 injuries [18]. For context, the national number of electrical power-line installers and repairers in May 2017 was 116650 [19], with 5730 in Florida. At the same time, the electric power generation, transmission, and distribution sector employed 17790 electrical engineers nationwide [20]. For further comparison, Folga et al. [21] found that a modern storm equivalent to 
the Great Miami Hurricane of 1926 would require 52000 mutual assistance workers with an expected restoration time of 2 weeks to 1 month. That is, the mutual assistance effort called upon to aid Florida was consistent with estimates established in the previous year for a regionally representative catastrophic event. By September $19^{t h}$, nine days after Irma made landfall, interruptions from the storm were reduced to less than 100000 customer accounts [22].

Hurricanes deliver multiple hazards to the communities they strike. Air pressure drops as the storm approaches, severe winds turn unsecured debris into missiles that can cause serious damage to life and structures, rains batter the hurricane's path, and storm surges can leave wide areas under water. While wind, rain, and flood waters can all impact the electric grid, models of hurricane damages often focus explicitly on wind stress [23-28].

Wind speed data is collected for a sample of Florida weather stations recorded in the National Centers for Environmental Information's Integrated Surface Data (ISD) dataset. Fig. 3a presents the physical locations of the 85 weather stations from which hourly wind speed data was pulled for the month of September 2017. Counties are coded according to the number of weather stations within their borders. The distribution of weather stations often coincides with airports and regions of relative population density. However, the coverage spans most of the state with the largest gaps located along the Florida-Georgia line and south-central Florida.

The wind speed information used in this study comes from meteorological terminal aviation routine weather reports (METARs) which are labeled as FM-15 in the raw data. Stations record wind speeds experienced at the time of each report. All stations are scheduled to report weather conditions at least once an hour, and some stations make as many as three reports an hour. We collapse the raw data to the hourly level, taking the maximum wind speed observed by each station in any given hour.

Extreme winds are capable of damaging the instruments deployed to measure weather conditions. Hurricane Irma caused some weather stations located in southern Florida to experience "complete failure, or loss of multiple functions" [29]. Consequently, some of the official means for recording local weather data were temporarily out of service at the time when wind speeds and new interruptions were expected to peak. Fig. 3a shows that one of the meteorological stations in northwest Florida experienced an outage for the duration of the study period. Another 10 stations experienced outages during at least $5 \%$ of their reporting times. Raw wind speed data is missing for roughly $5 \%$ of the over 80 000 observations in the weather station sample.

Fig. $3 b$ shows that weather station outages in Florida peaked between September $9^{\text {th }}$ and $12^{\text {th }}$. As many as 12 weather stations experience outages concurrently. Low-level idiosyncratic outages are also spread across the study period. These stations reported missing values for wind speed in periods where the true value was higher. The zero values are incorporated into the synthetic wind speed data used for the primary analysis in this manuscript. As a result, the true value of wind speed incident on the grid is likely higher than reported for some hours. Further discussion of the impacts of station outages can be found below.

For the purpose of this study, weather station point observations of operating conditions 


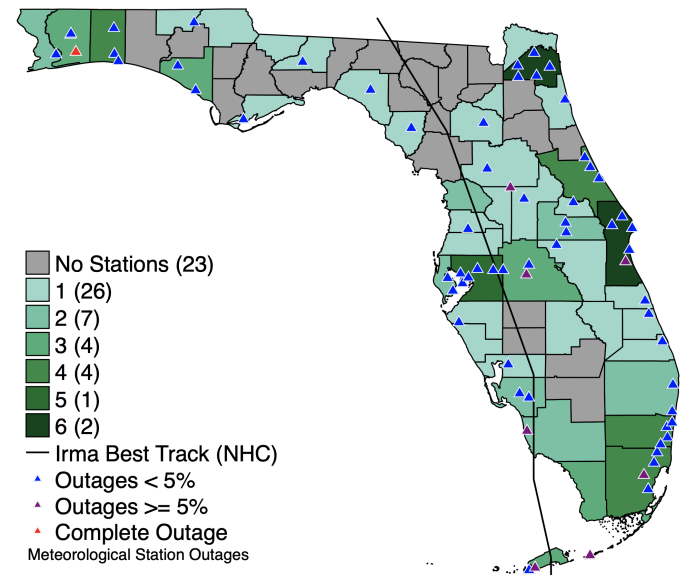

(a) Spatial distribution of weather stations and outages

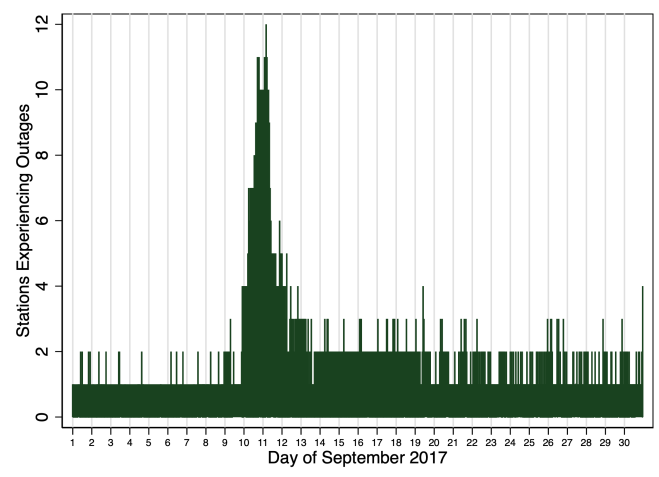

(b) Temporal distribution of weather station outages

Fig. 3. Weather station outages. (a) The spatial distribution of weather stations and outages, as well as Hurricane Irma's track. (b) The temporal distribution of weather station outages during Hurricane Irma.

must be translated into county-specific metrics. Hourly wind speeds were imputed for each county as a linear combination of the values reported by the network of weather stations in Florida for September 2017. These imputed wind speed values are then normalized with respect to the synthetic county-level sample of all hourly records for that month.

Shepard's method for spatial weighting was employed in the imputation process [30]. The power parameter ( $p=20$ ) was selected for the weighting function to strongly weight observations from relatively close weather stations. When a weather station experiences an outage, the relatively strong weighting of proximate point data sources will lead the adjacent synthetic wind speed series to approach zero values. In reality, the values obtained using Shepard's method do not reach exactly zero as distant wind stations not impacted by the outages still inform the synthetic values employed in the study. While increasing the weighting on distant stations improves observational fidelity around landfall, these benefits come at a tradeoff with respect to the county-level variance observed in the synthetic wind speed time series.

The storm center tracked along the west coast of Florida, but it is well-documented that in the northern hemisphere, tropical cyclones produce winds that tend to be strongest on their eastern side where the translational speed of the storm adds to their rotational velocity [31]. Fig. 4a plots actual customer service interruptions and synthetic wind speed values for Palm Beach County on Florida's east coast. Synthetic wind speeds in Palm Beach begin to rise above typical levels on September $8^{\text {th }}$ and continue to do so until sufficient station outages happen on the $10^{\text {th }}$ to effect synthetic wind speeds approaching zero. As weather station outages are remedied by restoration efforts, the regular fluctuations in wind speed can be observed again, starting on September $12^{\text {th }}$. The timing of these weather station outages reflect the same spatiotemporal patterns observed in our customer service 
interruption data. Peaks in weather station and electric grid outages are driven by similar wind-based data generating processes as Irma moved across Florida.

Fig. $4 \mathrm{~b}$ presents the maximum values of the synthetic wind speeds for each county as a number of standard deviations above the sample mean. Wind speeds reached their highest localized peak values in southern Florida near where Hurricane Irma made landfall. Top wind speeds fell as the hurricane moved over land and lost energy.

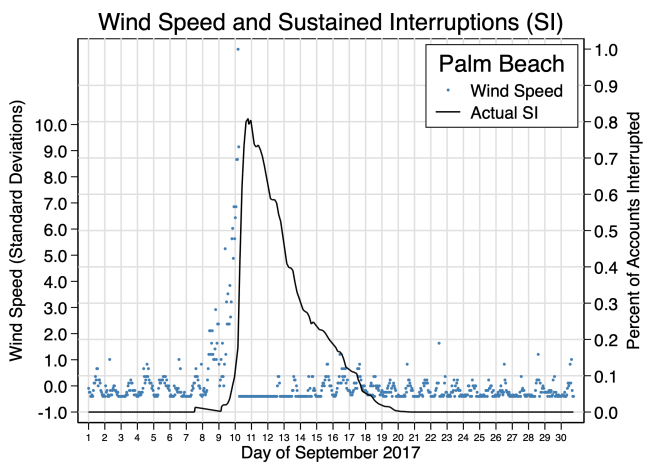

(a) Station outages and synthetic wind calculations

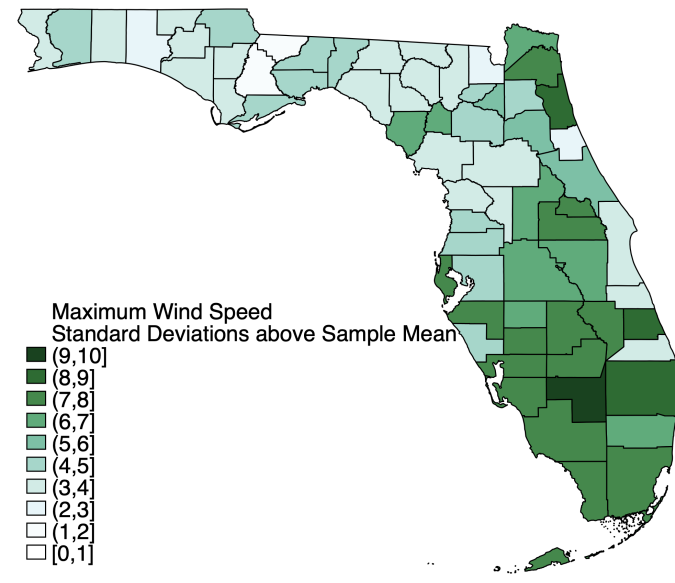

(b) County-level maximum synthetic wind speed

Fig. 4. Synthetic wind speed data. (a) Synthetic wind speed data and the percent of accounts interrupted for Palm Beach county Florida in September 2017. (b) Maximum synthetic wind speeds at the county level.

\subsection{Electric Service Interruptions}

Every sector of the economy uses electricity directly as an input to production and indirectly, embodied in the goods and services consumed from other sectors. Electricity is so integral to daily life, that some may take it for granted unless and until a service interruption occurs. Electric service interruptions can negatively impact health [32], disrupt business operations [33], lead utilities to lose sales revenue, and require restoration expenditures. Generally, the direct effects of electric service interruptions are better documented and understood then indirect effects. Interruption cost estimates for the individual and national level both exhibit high variance, indicating that context matters in determining how costly it is for a customer or community to lose power.

The cost of an individual account interruption rises with its duration [34]. For most customers, losing power for a few seconds or minutes is an inconvenience while sustained interruptions, on the order of hours or days can be very costly. In surveying recent interruption value estimates, Woo et al. [35] presents cost estimates for a 1-hour interruption of residential service that range from $\$ 0.42$ to $\$ 78.22$ with a mean of $\$ 15.56$. Their own study found the value of a 1 -hour residential service interruption to be $\$ 45$. 
In addition to scaling with the duration of the interruption, costs rise with the amount of load that is not served. All else equal, interruptions of a given duration will be costlier for larger consumers of electricity. Interruption costs may also be calculated on the basis of energy not served. Caves et al. [36] estimates the cost per hour of interruption at $\$ 4$ per $\mathrm{kWh}$ for customers in the industrial sector, which tends to be made up of larger consumers. Baik et al. [37] estimated willingness to pay for residential backup service at $\$ 0.75 / \mathrm{kWh}$ and $\$ 0.51 / \mathrm{kWh}$ for high and low priority applications respectively. Ideally, estimates of individual interruption costs are closely tied to the household or business production function.

In 2001, the annual national economic cost of interruptions and power quality phenomena was estimated at \$ 104 billion to $\$ 164$ billion [38]. LaCommare and Eto [39] found the annual economic cost of power interruptions and quality events in the U.S. to be $\$ 79$ billion in their base case, with maximum and minimum of $\$ 135$ billion and $\$ 22$ billion respectively. The Council of Economic Advisers [40] estimate the annual cost of severe weather related interruptions in the US to fall between $\$ 18$ billion and $\$ 33$ billion.

The term outage is often used colloquially, and sometimes synonymously with interruptions. To avoid confusion, this manuscript employs definitions from the Institute of Electrical and Electronics Engineers (IEEE) for interruptions, outages and related concepts, with the exception of directly quoted material [1]. Unless explicitly stated (as momentary), the interruptions should be understood to refer to sustained interruptions in this manuscript.

The interruption data employed in this study does not indicate the specific length of interruption for each individual customer account, instead only the total number of accounts currently experiencing interruptions is reported when the data is pulled from utility systems. Furthermore, unobserved hourly interruption data is imputed from observed values. Evaluation of interruption duration must therefore be conducted at the county or countyutility segment level.

The system average interruption duration index (SAIDI) is employed in reliability studies to measure the duration of interruptions experienced by an average customer of a utility system on an annual basis. The SAIDI is calculated using interruption data from periods in which the system did not experience extreme levels of stress. Fig. 5a presents a map of Florida counties coded by the average duration of interruptions experienced by customers in September 2017.

An alternative form of this index sometimes used in the literature is the STAIDI [41], where the modified abbreviation is intended to convey that it is being calculated for a single storm event and not the whole year. The remainder of this manuscript will use the term SAIDI while referring only to interruptions associated with Irma. The mean SAIDI value for counties in Florida during that month was 49 hours. In all counties, the average interruption per customer account lasted no longer than 1 week (168 hours). All but 12 of Florida's 67 counties experienced average interruptions of less than three days (72 hours). Fig. 5b presents the distribution of SAIDI values observed for different county-level segments of the grid in September 2017. County level aggregation masks the long right tail of the distribution, where a few segments of the grid experienced average interruptions 


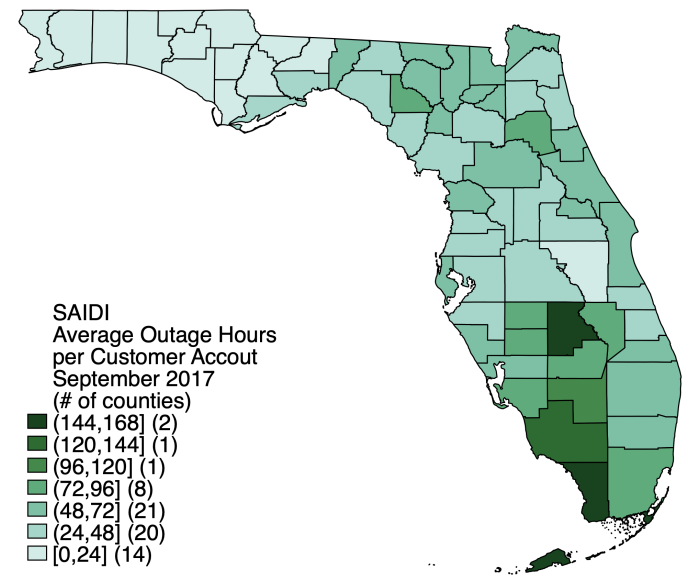

(a) September 2017 SAIDI for Florida counties

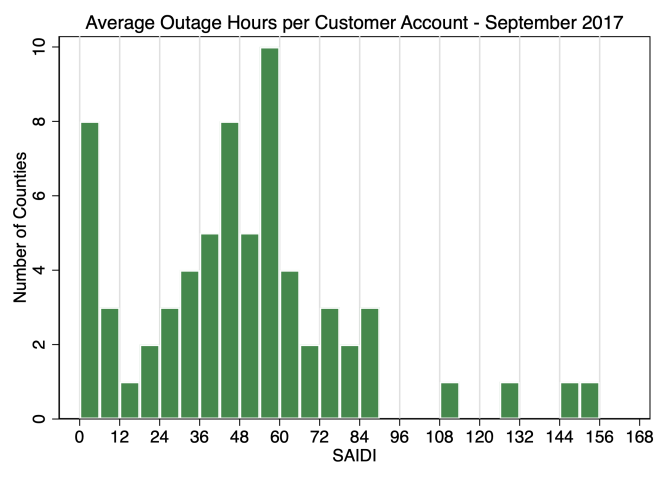

(b) Distribution of county-utility SAIDI

Fig. 5. System average interruption duration index. (a) Map of SAIDI values at the county level. (b) Histogram of SAIDI values for the sample of county-utility pairs.

beyond a week in duration.

Data on electric utility customer interruptions during Hurricane Irma, including observations for the period of September 7th, 2017 through September 28th, 2017 was obtained from the Florida Department of Emergency Management. Interruption data is recorded with a timestamp and is disaggregated to the level of county and power provider. All power providers that report data are classified as IOU, municipal utilities, or rural electric cooperatives. Some counties are served by many power providers, while other counties are served by more concentrated supplier networks.

Data is available for times when the reports were pulled from utility outage management systems. As such, the timing of available observations may be impacted by constraints on personnel and the data systems they use. Conducting any job during a hurricane is likely to be fraught with atypical challenges. Data system operation is no different. Interruption reports come in batches and are not reported for every hour. For hours in which counties or county-utilities do not report interruptions, missing values were imputed from non-missing values in the data. Some variation may not be captured in the interruption data employed for this study. As restoration work is conducted by teams fixing many distinct segments of the electric grid, customer interruption counts may remain static for some time while repairs are conducted, and then jump discretely after segments of the electric grid are reenergized. It is possible that interruption data was pulled at intervals which coincide with the completion of assorted restoration tasks.

Fig. 6a presents the total interruption count for all 67 counties over the course of September 2017. Sustained interruptions in Florida peaked on September 11th, impacting nearly 7 million customer accounts. Interruptions accumulated to the peak level within three days of the initial rise in wind stress. Seven days after peak interruptions, restoration efforts had returned the interruption share to less than $10 \%$ of its peak value. 


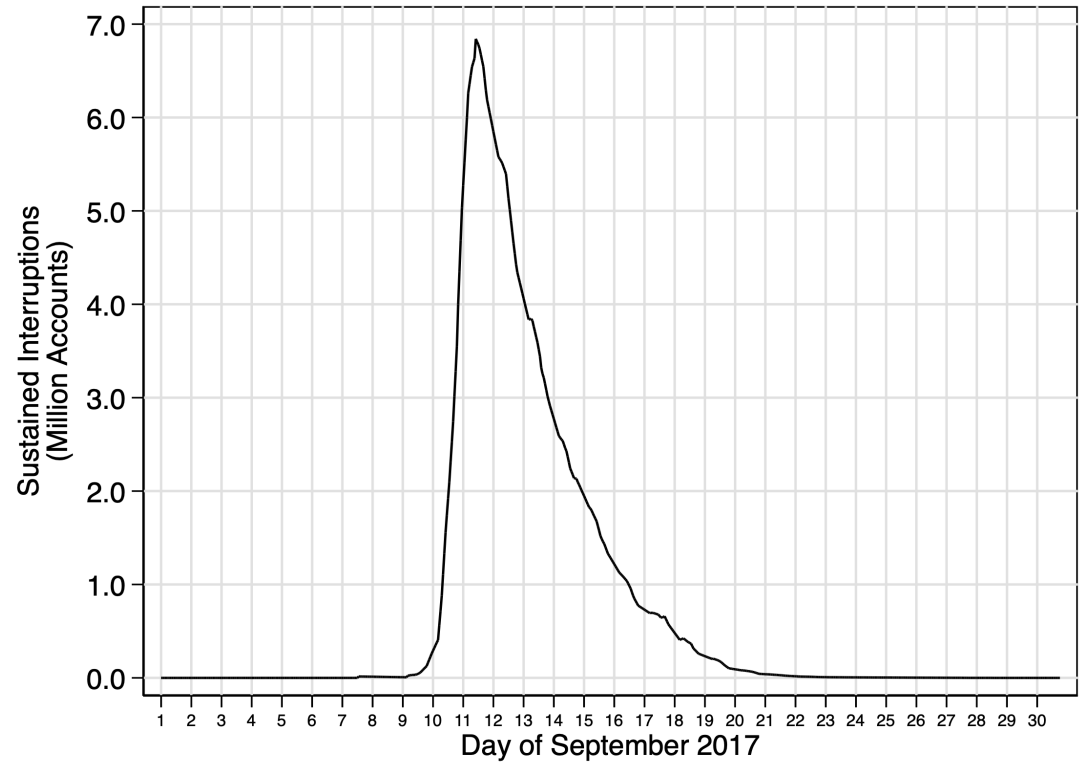

(a) Hurricane Irma service interruptions

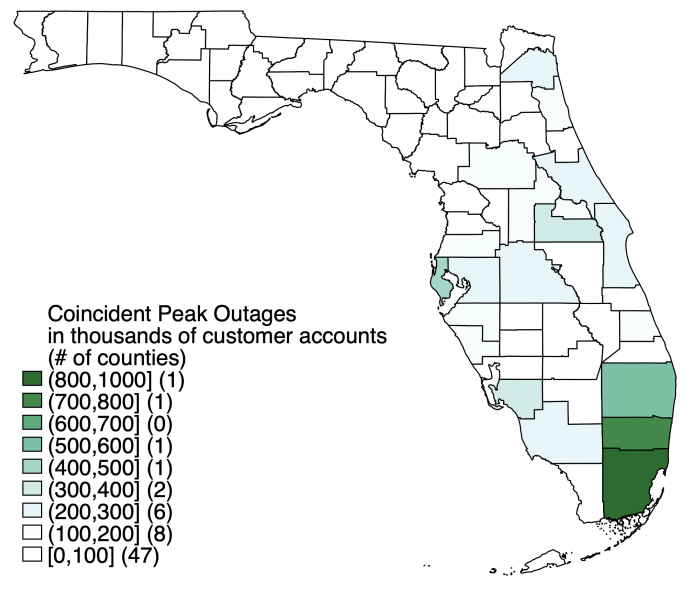

(b) Peak interruption counts

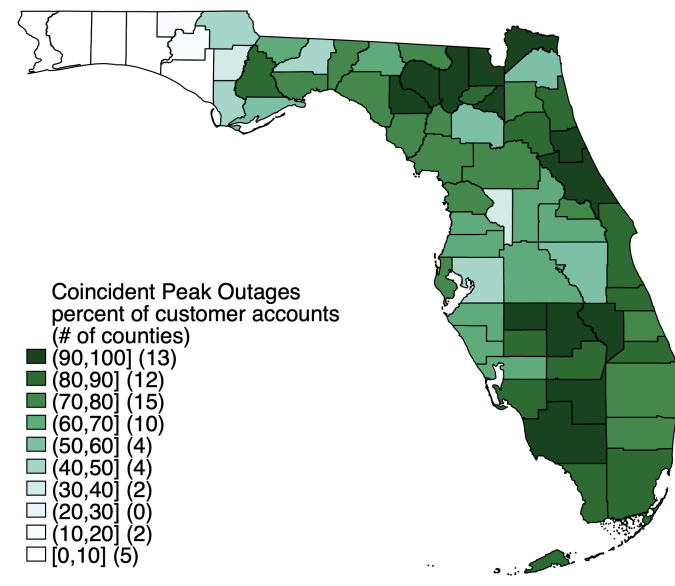

(c) Peak interruption shares

Fig. 6. Interruption summary. (a) Customer interruption counts for Florida in September 2017. (b) County-level interruption counts at the coincident peak. (c) Percent of accounts interrupted in each county at the coincident peak.

Fig. $6 \mathrm{~b}$ and Fig. $6 \mathrm{c}$ present the distribution of sustained interruptions to customer service accounts across the geography of Florida. Fig. 6b shows that the peak number of interruptions is clearly concentrated in the densely-populated southeast coast of the state. Fig. 6c shows that while total interruptions were highest in one corner of the state, only the northwest portion of the Florida panhandle escaped Hurricane Irma without suffering interruptions to large shares of electricity customers. Of the 67 counties in Florida, 13 experienced peak interruptions that impacted greater than $90 \%$ of customers. On the other 
hand, only 7 counties had peak interruptions of less than $30 \%$ of customers.

\subsection{Ancillary Data Resources}

Additional data on the built environment and demographics is acquired to evaluate the robustness of the main findings. The population data used in this manuscript comes from the Annual Estimates of the Resident Population produced by the U.S. Census Bureau. Land area is reported for counties circa 2011 by the Census Bureau. Median income data for 2017 is obtained from the U.S. Census Bureau, Small Area Income and Poverty Estimates program. The data on building vintage comes from the U.S. Census Bureau's 2016 American Community Survey. Data from FERC Form 1 filings is obtained from the Public Utility Data Liberation Project of the Catalyst Cooperative and is available at https://github.com/catalyst-cooperative/pudl. To test the robustness of our findings we obtained alternative wind data from the ERA5 dataset produced by the European Centre for Medium-Range Weather Forecasts.

\section{Empirical Strategy}

Practical considerations inform our choice of empirical strategy for investigating the impact of interoperability on distribution grid resilience to hurricane induced service interruptions. These considerations are primarily related to the distribution of our outcome variable and the presence of unobserved heterogeneity in service territory topology and demography. We employ the FEP estimator to model sustained interruptions conditional on hurricane wind stress, and organizational interoperability levels as proxied by advanced metering penetration.

The Poisson estimator has been used to evaluate a wide range of physical and economic phenomena. Examples in the literature have used variations of the Poisson estimator to model hurricane-induced customer interruptions [42-45], airline safety performance [46], highway safety policy [47], and patterns of international trade [48-50].

Unobserved heterogeneity in service territory topology and demography is a latent challenge to conducting reduced-form modelling of sustained interruptions. A standard crosssectional analysis might produce inconsistent estimates of the effects of interest if unobservable characteristics are related to explanatory variables in a systematic manner [51]. Panel (longitudinal) data models have been successfully employed to control for unobserved individual-specific heterogeneity $[46,52,53]$.

We are interested in estimating the expected mean of outcome variable $y_{i t}$, conditional on observable covariates, $x_{i t}$, and an unobserved effect, $\theta_{i}$, where $t$ indexes time and $i$ is the index for region. Borrowing notation from Wooldridge [51], Eq.(1) presents the conditional expectation of our outcome variable with the unobserved effect entering multiplicatively.

$$
\begin{aligned}
& E\left[y_{t} \mid \theta, x_{t}\right]=\theta m\left(x_{t}, \beta\right) \\
& \text { for } t=1,2, \ldots, T
\end{aligned}
$$


We assume the common exponential form for the parametric function $m\left(x_{t}, \beta\right)$. Taking $\theta=\exp (\phi)$ implies the following functional form for the conditional expectation.

$$
\begin{aligned}
& E\left[y_{t} \mid \theta, x_{t}\right]=\exp \left(\phi+x_{t} \beta\right) \\
& \text { for } t=1,2, \ldots, T
\end{aligned}
$$

The crucial assumption of the strict exogeneity of $x_{i t}$ conditional on $\theta_{i}$ is maintained and stated as follows.

$$
\begin{aligned}
& E\left[y_{t} \mid \theta_{i}, x_{i 1}, \ldots, x_{i T}\right]=\theta_{i} m\left(x_{i t}, \beta\right) \\
& \text { for } t=1,2, \ldots, T
\end{aligned}
$$

Wooldridge [54] shows that Eq. (3) is the only assumption that needs to hold for the FEP estimator to produce consistent estimates of $\beta$. The FEP is robust to over-dispersion of our count data. Furthermore, there are no restrictions against arbitrary dependence between $y_{i t}$ and $y_{i r}$ for $t \neq r$, implying robustness of the FEP to serial dependence [51]. This last property is important as counts of service interruptions are likely to exhibit high levels of serial dependence.

Our raw dependent variable is the count of hurricane-induced sustained interruptions in each county or county-utility region in September 2017. Only the number of customer accounts experiencing interruptions at the time when data is pulled is observable in the data. That is, we observe the joint failure-and-recovery process, as exhibited by the number of customer nodes in a failure state [43]. Accounts that lose power momentarily between observation times, only to regain service before the next data pull, are not observed in our data. As data is reported several times each day, but not at every hour, values for intervening hours are imputed from observed data in a simple linear manner. As a result, a constant slope to interruption curves is assumed between observation times, and consecutive hours may thus report the same value for changes in the interruption total.

Hours for which new interruptions are dominating restoration efforts are described as subject to a storm regime, while a restoration regime is active in hours where net change in account interruptions is negative. These two regimes are considered to be different data generating processes. To evaluate system resilience rather than reliability, we mostly focus on the storm regime, that is, the subsample of hours in which counties (county-utilities) experience a non-negative net change in total accounts experiencing interruptions.

The dependent variable employed in the analysis presented in this manuscript takes on positive values when the total interruption count is rising within a given hour and is coded to zero if total interruptions remain static or fall. There are many zeros in the dependent variable as no hurricane-induced interruptions are suffered early in the month before the storm arrives, or after restoration is complete. However, during the peak of the storm the most populated counties experienced tens of thousands of interruptions concurrently. The presence of zero values in dependent variables has long been a known challenge for 
empiricists working in the area of international trade, leading to the refinement of applied methods $[48,55]$.

Fixed effects account for time invariant unobserved heterogeneity in service territory topology and demography. AMI penetration is taken to be time invariant within our study period. Logically, no new smart meters are being installed during the height of the storm, and restoration efforts generally rebuild the distribution grid as closely as possible to its pre-event state. In our core specification, an estimate of the resilience impacts of interoperability is recovered by interacting AMI penetration with the main determinant of hourly interruption counts, the square of wind speed. This model specification allows for the determination of whether the resilience of the distribution grid to wind of a given velocity is modulated by the extent of interoperability as proxied by AMI. The FEP enjoys several statistical properties that render it appropriate for the analysis of sustained power interruptions $[51,56]$.

Equation (4) details our core regression specification, for which results are presented in Table 1.

$$
E\left[y_{i t} \mid \theta_{i}, x_{i t}\right]=\theta_{i} \exp \left(\beta_{1} x_{1 i t}+\beta_{2} x_{1 i t} x_{2 i}+\varepsilon_{i t}\right)
$$

Let our measure of the synthetic wind speed squared for region $i$ in time $t$ be denoted $x_{1 i t}$. The share of customer accounts served by AMI in each region is denoted $x_{2 i}$. The fixed effect is denoted $\theta_{i}$. The time-invariant AMI variable is interacted with squared wind speed to recover estimates of the operational resilience impact of the advanced distribution technology.

Consider the two boundary scenarios in which AMI penetration is zero, $x_{2 i}=0$, and complete, $x_{2 i}=1$. When these two scenarios hold, Eq. (4) simplifies into the following forms, presented in Eq. (5). Note that the region index in second expression in Eq. (5) is changed to $j$. This notation reflects the fact that we only observe the AMI penetration of each region at its given level and therefore cannot explicitly compare the same region to itself with different levels of AMI.

$$
\begin{aligned}
E\left[y_{i t} \mid \theta_{i}, x_{2 i}=1\right] & =\exp \left(\beta_{1} x_{1 i t}+\beta_{2} x_{1 i t}+\varepsilon_{i t}\right) \\
E\left[y_{i t} \mid \theta_{j}, x_{2 j}=0\right] & =\exp \left(\beta_{1} x_{1 j t}+\varepsilon_{j t}\right)
\end{aligned}
$$

Now suppose we are interested in the implied ratio of the expected value of interruptions for region $i$ at time $t$ for the complete AMI scenario relative to zero AMI scenario. This requires relaxing the restriction on self-comparison. Effectively we must make the assumption, however tenable, that two regions, $i, j$, differ only in AMI penetration, allowing us to proceed as if all else is equal between our two scenarios. That is, assume $\theta_{i}=\theta_{j}$, and $x_{1 i t}=x_{1 j t}$. We can then write the ratio of interest as in Eq. (6).

$$
\frac{E\left[y_{i t} \mid \theta_{i}, x_{2 i}=1\right]}{E\left[y_{i t} \mid \theta_{i}, x_{2 i}=0\right]}=\frac{\theta_{i} \exp \left(\beta_{1} x_{1 i t}+\beta_{2} x_{1 i t}+\varepsilon_{i t}\right)}{\theta_{i} \exp \left(\beta_{1} x_{1 i t}+\varepsilon_{i t}\right)}
$$


Let $\frac{E\left[y_{i t} \mid \theta_{i}, x_{2 i}=1\right]}{E\left[y_{i t} \mid \theta_{i}, x_{2 i}=0\right]}=\frac{1}{R_{i t}}$. Applying this identity and simplifying the expression in Eq. (6) we obtain the following expression in Eq. (7).

$$
\begin{aligned}
\frac{1}{R_{i t}} & =\frac{\exp \left(\beta_{1} x_{1 i t}+\beta_{2} x_{1 i t}+\varepsilon_{i t}\right)}{\exp \left(\beta_{1} x_{1 i t}+\varepsilon_{i t}\right)} \\
\frac{1}{R_{i t}} & =\exp \left(\left(\beta_{1} x_{1 i t}+\beta_{2} x_{1 i t}+\varepsilon_{i t}\right)-\left(\beta_{1} x_{1 i t}+\varepsilon_{i t}\right)\right) \\
\frac{1}{R_{i t}} & =\exp \left(\beta_{2} x_{1 i t}\right)
\end{aligned}
$$

Equation (7) states that the ratio of expected interruptions between the complete and zero AMI penetration scenarios is equal to the exponent of the product of the coefficient on the interaction term, $\beta_{2}$, and the level of prevailing wind shock, $x_{1 i t}$. Now assume $\mathrm{a}+1$ standard deviation shock (increase) in squared wind speed, $x_{1 i t}=1$. The ratio of expected interruptions for such a shock is presented in Eq. (8).

$$
\begin{aligned}
\frac{E\left[y_{i t} \mid \theta_{i}, x_{1 i t}=1, x_{2 i}=1\right]}{E\left[y_{i t} \mid \theta_{i}, x_{1 i t}=1, x_{2 i}=0\right]} & =E\left[\frac{1}{R_{i t}} \mid x_{1 i t}=1\right] \\
& =\exp \left(\beta_{2} x_{1 i t}\right) \\
& =\exp \left(\beta_{2}\right)
\end{aligned}
$$

\section{Results}

We estimate the conditional expectation of the mean for arriving customer interruptions using a FEP regression applied to longitudinal data and discover a statistically significant reduction in expected customer outages as interoperability increases. Results from the core regression specification are presented in Table 1. Our core regression specification models the conditional expectation of customer interruptions as the exponent of our normalized wind speed variable, and the interaction of that variable with our proxy for interoperability (the share of customers that are connected to the grid through AMI). For segments of the grid without any customers served through AMI, the expected value of long-duration customer interruptions grows by $59 \%$ for each standard deviation increase in $W^{2}$. Customer outages grow at only $90 \%$ of that rate in areas of the grid with full AMI deployment, which amounts to just a $44 \%$ increase $(1.588 \times 0.905=1.437)$ in expected interruptions for each standard deviation increase in $W^{2}$ when AMI deployment is complete.

Our proxy for interoperability modulates the effect of wind on the expected number of customer interruptions. For every additional 100 customer accounts expected to lose power due to a one standard deviation wind shock in the absence of AMI deployments, only 90 customer accounts are expected to lose power when AMI deployment is complete. Or, 10 $\%$ of expected additional interruptions are mitigated for segments in which AMI is fully 
deployed. This ratio of expected interruptions is multiplicative in nature, so as wind speeds increase and even more customer accounts are expected to lose power, the percent of interruptions mitigated under full deployment is expected to continue growing at a diminishing rate. The moderating effect is present over the observed range of the wind regime and should not necessarily be construed to hold in the extremity of double-digit standard deviation wind shocks. These results proved robust against numerous other factors, including building stock vintage, population density, and median household income.

Fig. 7a presents the number of service interruptions arriving in counties within an hours' time as the size of a marker plotted against the square of wind speed and AMI penetration. The largest arrivals of new interruptions are associated with high winds impacting regions with relatively low levels of AMI. However, even the regions with high levels of AMI penetration are not uniformly able to prevent the experience of injury from a storm such as Hurricane Irma.

A central finding of this study is that greater interoperability, as measured by AMI penetration, improves the resilience of customer accounts to sustained interruptions as local resources are more effectively coordinated and capable of taking self-healing actions. Fig. $7 \mathrm{~b}$ demonstrates this by comparing the observed interruption trends for regions with greater than or less than 50 percent AMI deployment, where observed customer interruptions clearly rise slower as a function of squared wind speed for counties with higher AMI penetration.

Table 1 in the manuscript displays coefficients as incidence rate ratios, that is, in the form $\exp \left(\beta_{2}\right)$. For the County-Utility level regression, we estimate $\beta_{2}=-0.0999$ implying $\exp \left(\beta_{2}\right)=0.905$. Returning to Eq. (7), we can estimate the incidence rate ratio between complete and zero AMI penetration at higher levels of wind stress. For a 2 standard deviation increase in the squared wind speed metric, $x_{1 i t}=2$, the incidence rate ratio for interruptions between complete and zero AMI deployment falls, to $\exp \left(\beta_{2} \times 2\right)=0.905^{2}=0.819$. Notice that from zero to one standard deviation of wind stress, the interruption incidence rate ratio between scenarios falls from 1 to 0.905 , or $9.5 \%$ and 9.5 percentage points. From one to two standard deviations of wind stress the ratio falls from 0.905 to 0.819 , still $9.5 \%$ reduction from the new base, but now only 8.6 percentage points. The moderating role of AMI increases in percent terms for stronger levels of wind stress, but the incremental reduction with each additional standard deviation of wind stress diminishes.

There may be spatial dependence in weather and interruption data as the conditions afflicting adjacent segments of the distribution grid are likely correlated. Furthermore, restoration efforts on one segment of the grid could impact restoration progress on neighboring segments. As a robustness check, the standard errors for the county level core regression were also estimated using an alternative method accounting for time invariant spatial dependence [57]. The $p$-values estimated for both the squared wind speed and AMI interaction coefficients were both 0.000 when employing the alternative estimation technique. To further explore the relative experiences of neighboring counties with similar wind speeds and different AMI shares, select pairwise comparisons of adjacent counties are presented in Fig. A3-A5, which is found in the supplementary materials. 


\section{Sustained Interruptions by AMI Share and Wind Speed}

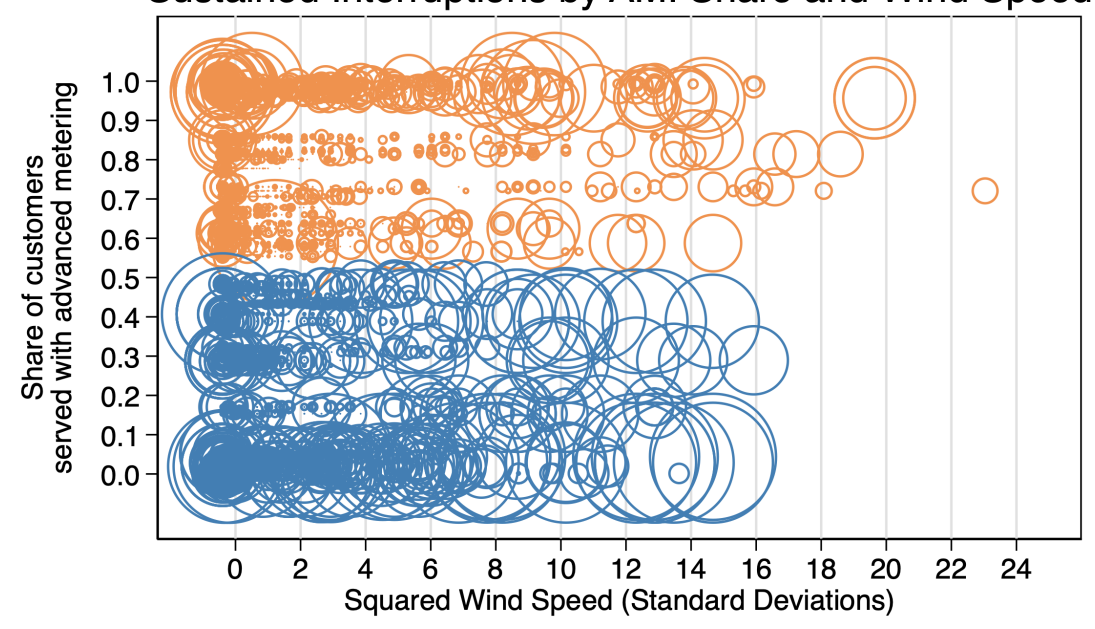

$\circ \mathrm{AMI}>50 \% \quad \circ \mathrm{AMI}<=50 \%$

Plot markers are proportional to the number of customer interruptions sustained in an hour.

(a) Interruptions by AMI share and wind speed

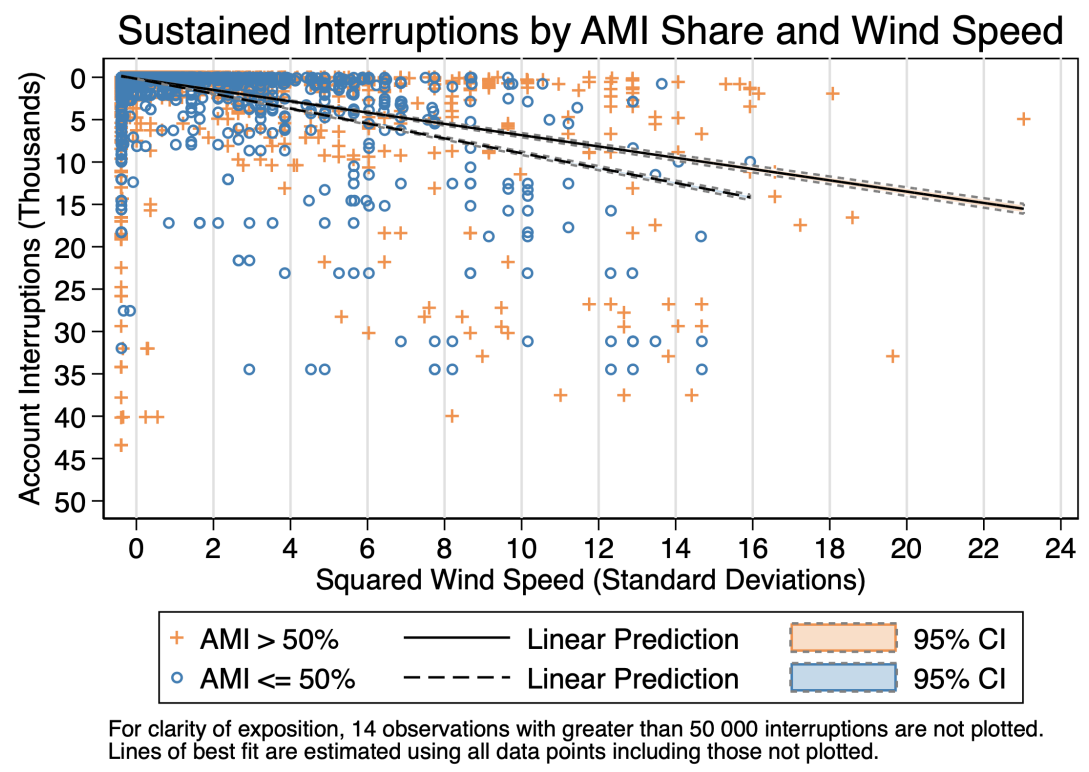

(b) Resilience differential

Fig. 7. Graphical representation of core results. (a) The number of interruptions sustained in an hour, decomposed by wind speed and the share of customers served by AMI. (b) The differential in resilience to interruptions exhibited by segments of the grid that had AMI penetrations above and below $50 \%$. 
Table 1. Conditional expectation of customer interruptions

\begin{tabular}{lcc}
\hline Dependent Variable: $\Delta$ Interruptions & (County-Utility) & (County) \\
\hline Squared Wind Speed $\left(W^{2}\right)$ & $1.588^{* * *}$ & $1.595^{* * *}$ \\
& $(0.0000)$ & $(0.0000)$ \\
$W^{2} \times$ AMI Share & $0.905^{*}$ & $0.904^{*}$ \\
& $(0.0120)$ & $(0.0213)$ \\
\hline Observations & 144065 & 47904 \\
$B I C$ & $4.744 \mathrm{e}+07$ & $4.405 \mathrm{e}+07$ \\
\hline$p$-values in parentheses. ${ }^{*} p<0.05,{ }^{* *} p<0.01,{ }^{* * *} p<0.001$ & \\
Coefficients reported as incidence rate ratios. & \\
\hline
\end{tabular}

\subsection{Counterfactual Analysis}

Crucial questions communities ask after enduring hurricanes are what have we been doing to prepare for this, did it work, and how do we value the associated costs and benefits? In response to the first question, one set of strategies for contending with exogenous stress on the distribution grid is to improve interoperability so that the system response may be more coherent and robust than what is possible when employing less coordinated resources and capabilities. We present evidence in support of an affirmative answer to the second question regarding the efficacy of interoperability investments in improving operational resilience. Now we turn to the third matter of valuations.

Having established that interoperability correlates with resilience to sustained interruptions, our attention turns to determining the practical size of the effect for the Florida distribution grid. To estimate the impacts of interoperability on the operational resilience of the distribution system in Florida against the stress of Hurricane Irma, counterfactual scenarios must be developed. Counterfactuals are, by definition, unknowable. However, the models developed in this manuscript and the estimates they produce may be leveraged to construct logical and reasonable scenarios for comparison and discussion.

Each of the counterfactual scenarios model hourly county-level interruptions as the product of observed values and an adjustment factor. The adjustment factor is a function of the wind speed encountered and the gap between actual and counterfactual AMI penetration. We approach each counterfactual with the same functional form, varying only the hypothetical level of our interoperability proxy.

We observe that the partial derivative of expected sustained interruptions with respect to wind speed is positive and the cross partial derivative of sustained interruptions with respect to wind speed and AMI penetration is negative. The core regression model is fit separately to two subsamples. The first subsample contains counties with greater than 50 $\%$ AMI penetration and the second subsample contains all other counties in Florida. Table A1 in the supplementary materials details the strong level of covariate-balance between the two subsamples. The ratio of expected interruptions between the low AMI and high AMI 
cases for a given level of squared wind speed is denoted $R_{i t}$.

Counterfactual interruptions $\left(I_{i t}^{C F}\right)$ in any hour are the product of actual interruptions $\left(I_{i t}^{A}\right)$ and an adjustment factor $\left(A_{i t}=R_{i t}^{G_{i}}\right)$. The adjustment factor is calibrated in line with the difference between the AMI shares in the actual and counterfactual scenarios using the exponent $G_{i}$. Let $G_{i}=\left(M_{i}-\widehat{M}\right) / H$, where $H$ denotes the difference between the average AMI share for counties with more than $50 \%$ AMI $(\bar{M})$ and the average AMI share for counties with less than or equal to $50 \%$ AMI $(\underline{M})$. Among Florida counties, $\bar{M}=0.831$ and $\underline{M}=0.194$. Let the share of customers served by AMI in county $i$ and the hypothetical AMI share under evaluation be denoted $M_{i}$ and $\widehat{M}$ respectively. The hypothetical AMI share is zero in $C F_{0}$, one in $C F_{1}$, and equal to the state-wide mean of $0.574 \mathrm{in} C F_{M}$. Theoretically, $G_{i}$ is bounded by positive and negative one. In practice, for this study, $G_{i} \in[-0.90,0.67]$.

In counterfactual scenarios where a county's hypothetical AMI penetration is altered upwards of actual levels, expected interruptions fall for a given level of wind speed. When hypothetical AMI penetration is less than actual levels, expected interruptions will rise conditional on wind stress.

The counterfactual interruption counts are bounded by zero and the total number of customer accounts. If zero interruptions were sustained by a county in a given hour, the multiplicative adjustment factor ensures the counterfactual interruptions value is also zero. However, it is possible that the counterfactual estimate would suggest the sustaining of more outages than there are accounts in a given county. To remedy such problems, the additional outages for the zero AMI-share counterfactual are capped at the level of accounts not experiencing sustained outages in the actual data.

After establishing the number of additional sustained outages expected in each hour, restoration patterns must be mapped into the counterfactual series. These counterfactual series are assumed to exhibit substantially similar persistence relative to the observed data series, only obtaining different peak levels of service interruptions. Counterfactual restoration patterns are modeled to echo the percent changes in interruptions observed in the actual data during the restoration regime. Next, the county level integral of account interruptions is obtained for observed and counterfactual scenarios, enabling the evaluation of interoperability impacts on the operational resilience and performance of the distribution grid. Dividing the total number of interruption hours by the number of customer accounts in each county produces an estimate of the SAIDI in each counterfactual scenario.

Counties with high levels of AMI penetration consistently outperformed mean counterfactual $\left(C F_{M}\right)$ expectations, suffering fewer customer interruption hours than are expected if they performed commensurate with regions that have the state-wide average AMI penetration. This outcome follows directly from the core findings. Walton County, with nearly complete AMI deployment, enjoyed a SAIDI that would have been $33 \%$ higher if it only enjoyed the state-average level of AMI penetration. On the other hand, Monroe County could have reduced its SAIDI by $13 \%$ if it increased performance in line with AMI deployment at the state average.

The difference between the actual observed SAIDI value for each county and that SAIDI which would be expected if the county had average AMI penetration-and asso- 
ciated interoperability_provides a measure of system performance ( $\Delta$ SAIDI). Fig. $8 \mathrm{a}$ and Fig. 8b present observed and counterfactual series of sustained interruptions for two counties with high and low interoperability. Had the county with a high AMI penetration performed as though it enjoyed only average interoperability we would expect customer average interruption duration to be $57 \%$ longer than what was observed. In the county with low AMI penetration, we would expect a $46 \%$ shorter average interruption duration if interoperability was improved in line with the state-wide average.

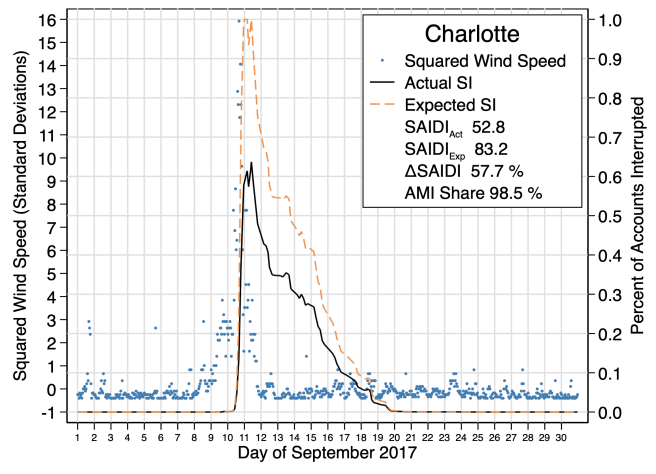

(a) High-interoperability county

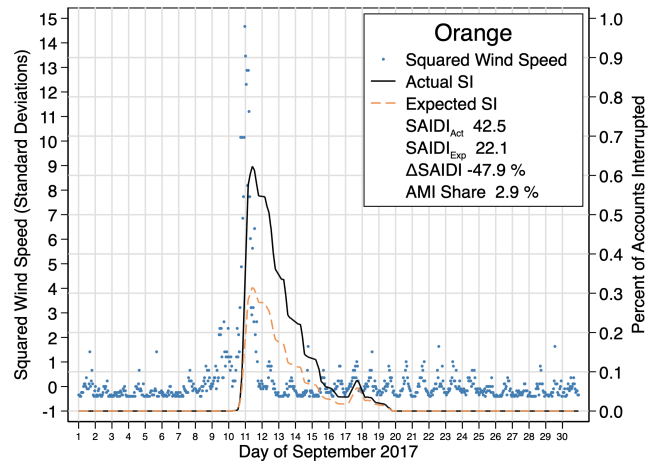

(b) Low-interoperability county

Fig. 8. Observed and modeled sustained interruptions (SI) for: (a) High-interoperability county, and (b) Low-interoperability county.

Fig. 9a and Fig. 9b present data on AMI penetration and $\Delta$ SAIDI for the highest and lowest decile of counties with respect to each variable. Counties with the highest AMI penetration consistently out-perform counterfactual expectations, meaning they consistently experience substantially fewer sustained outages than would be expected of a Florida county with average interoperability. Counties with low AMI penetration exhibit similarly consistent underperformance.

Fig. 10 displays a map of Florida counties with counties coded according to the percent increase in the SAIDI if their performance had been commensurate with a uniform distribution of AMI at the state average level of 57.4 percent. Counties coded green performed better than expectations associated with $C F_{M}$, while counties coded brown experienced higher SAIDI values than would be expected with the uniform distribution of AMI. An increase in the SAIDI value indicates that the average electric customer would experience longer interruptions. Therefore, positive values in Fig. 10 indicate that actual performance exceeded expectations associated with the $C F_{M}$ model.

Fig. 11 presents a comparison of actual and counterfactual coincident peak interruptions for counties in Florida that occurred midday on September 11, 2017. Under the counterfactual scenario $C F_{0}$, customer interruptions across southern Florida could have been much more widespread. If the whole Florida grid had performed commensurate with regions enjoying a full deployment of AMI, as is the case with counterfactual scenario $C F_{1}$, coincident peak interruptions would have been considerably lower. 


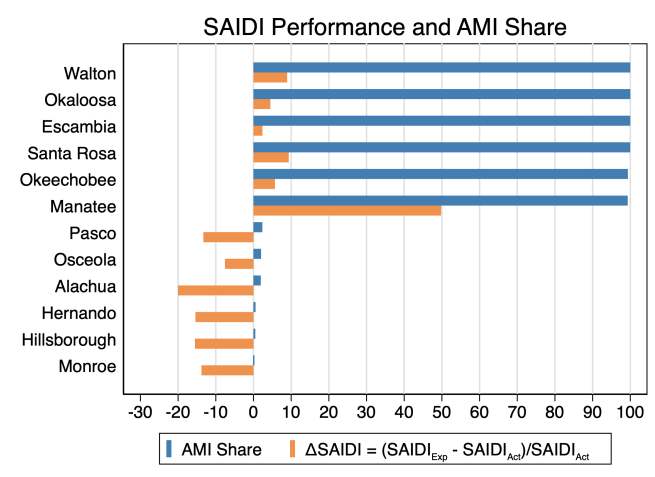

(a) Counties ranked by AMI share

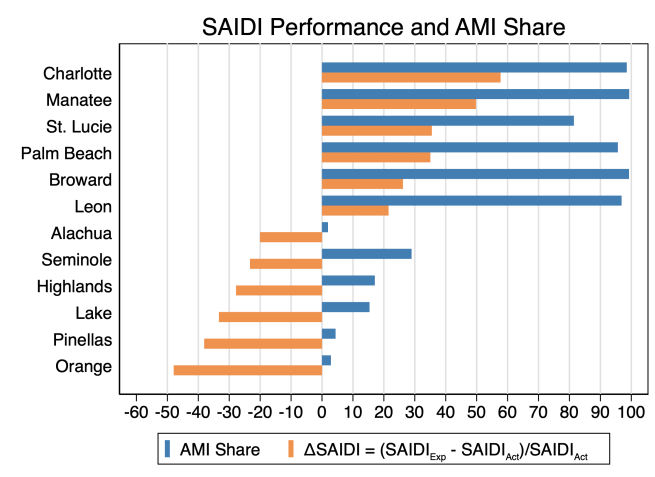

(b) Counties ranked by $\Delta$ SAIDI

Fig. 9. Actual and expected performance for counties: (a) ranked by AMI share, and (b) ranked by $\triangle$ SAIDI.

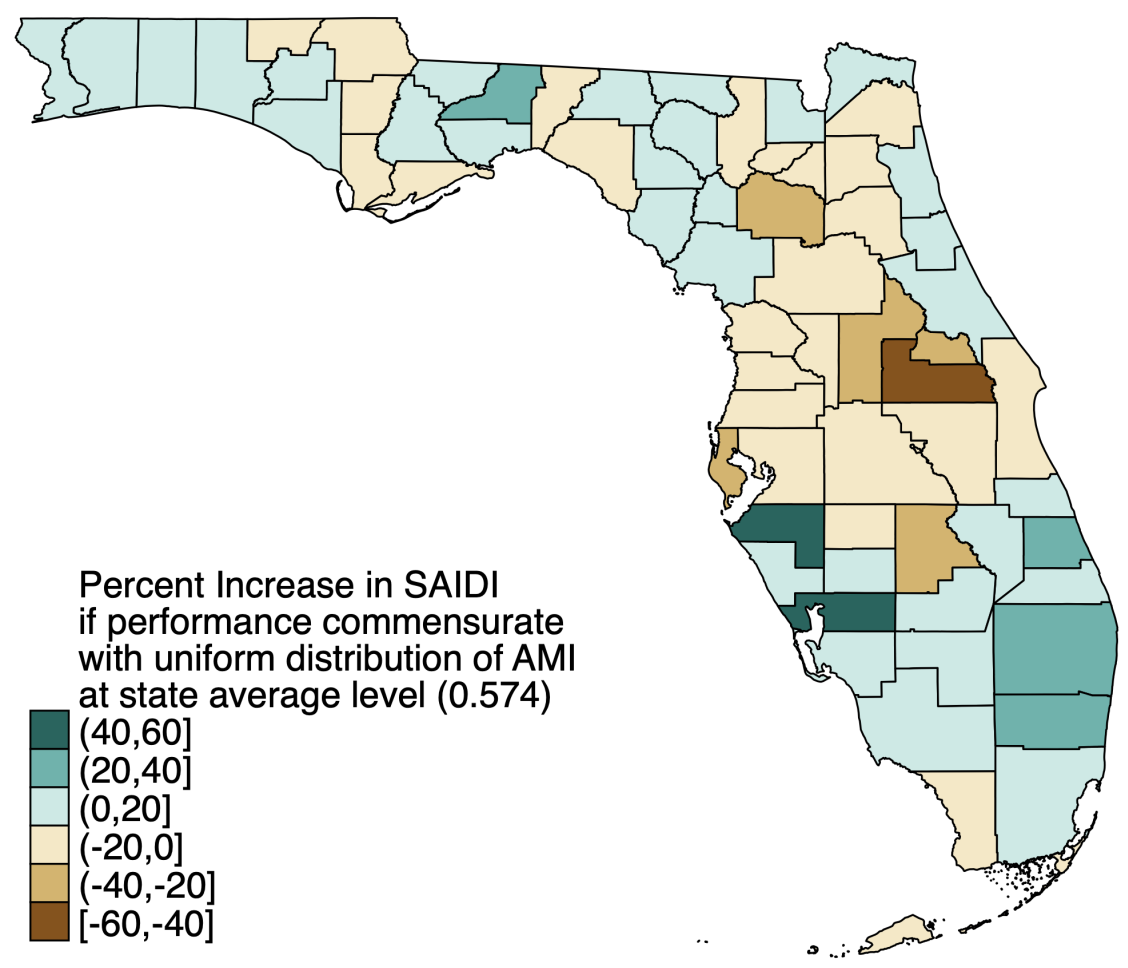

Fig. 10. Performance relative to $C F_{M}$ expectations

Across the state of Florida, Hurricane Irma caused over 556 million customer interruption hours leading to a SAIDI estimate of 52.9 hours during September 2017. This estimate differs from many versions of the SAIDI that may omit interruptions that are caused on major event days. Our SAIDI metric focuses exclusively on interruptions due to hurricane induced outages. Table 2 presents estimates of the number of interruption hours, SAIDI, and interruption costs for each counterfactual as well as the values actually observed. Next, we 


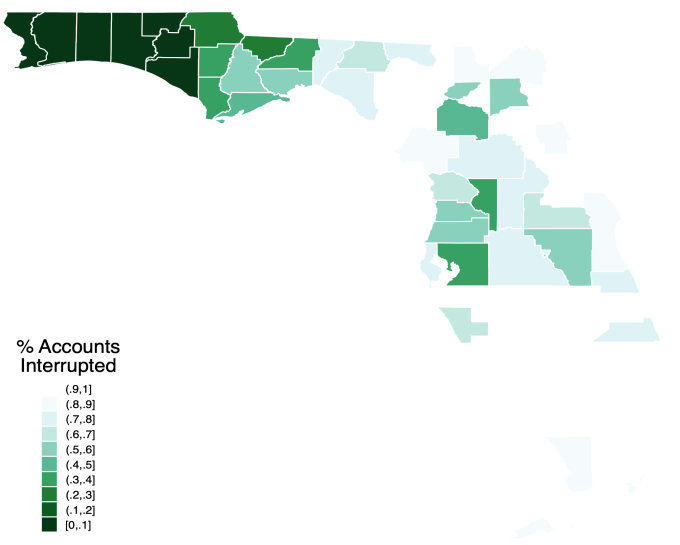

(a) Counterfactual $C F_{0}$

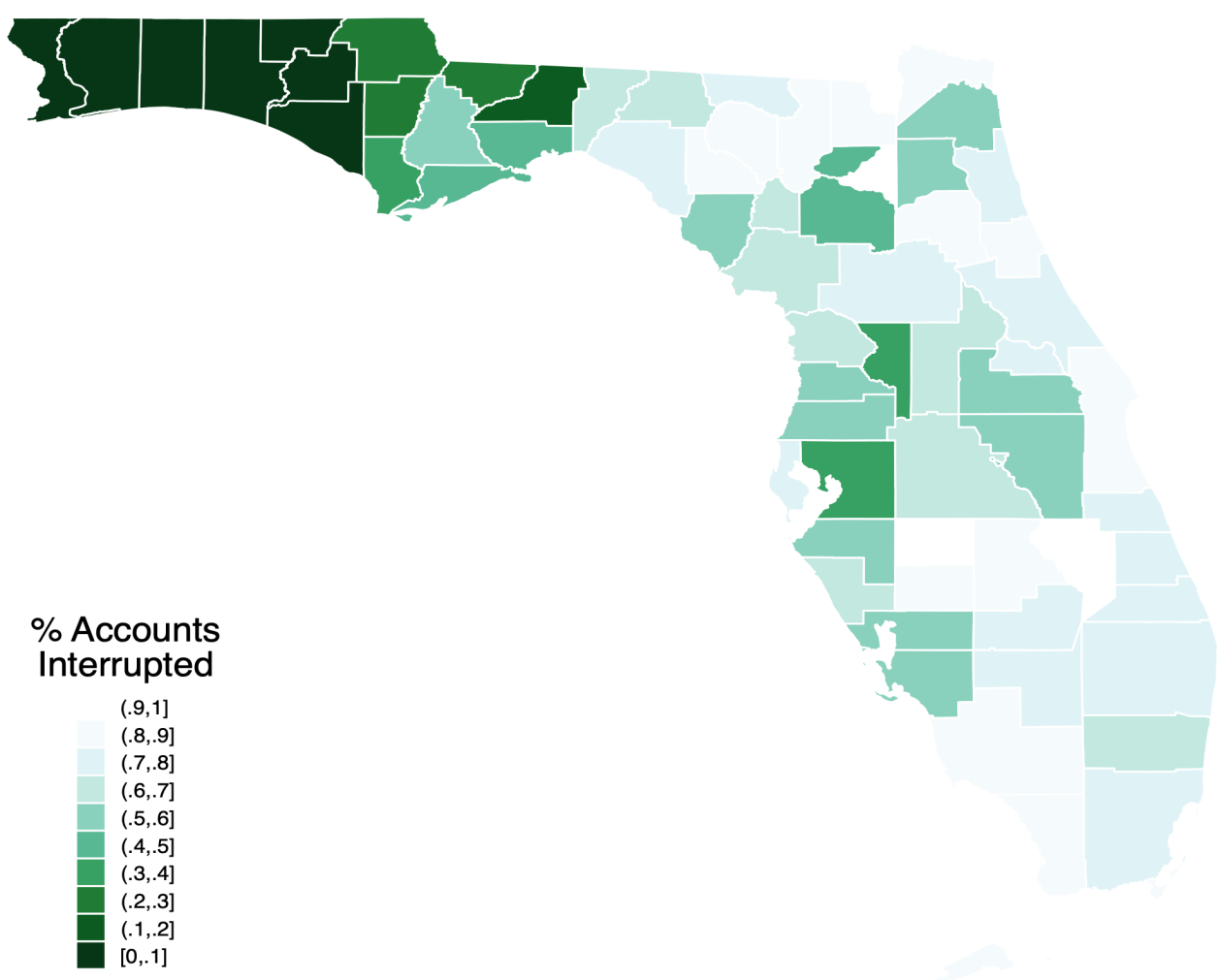

(c) Actual observations

Fig. 11. Peak coincident interruptions for: (a) counterfactual $C F_{0}$, (b) counterfactual $C F_{1}$, (c) actual observations.

compare actual interruptions and SAIDI values with those estimated for each of the three counterfactual scenarios. These comparisons are presented in Table 3 .

The first counterfactual investigates the benefits to operational resilience that have already been realized through the deployment of AMI. We estimate the counterfactual inter- 
ruption series by setting $\widehat{M}=0$. The difference in performance metrics between the actual events and the $C F_{0}$ scenario constitutes an estimate of the benefits gained from deploying advanced distribution technologies.

Table 2. Actual and counterfactual outcomes

\begin{tabular}{lrrrrr}
\hline & Hourly Cost $(\$)$ & Actual & $C F_{0}$ & $C F_{M}$ & $C F_{1}$ \\
\hline Total interruption hours (millions) & & 557 & 669 & 570 & 464 \\
Florida SAIDI (Hours in 9.2017) & & 52.9 & 63.5 & 54.2 & 44.1 \\
\hline Total interruption costs & 0.50 & 278 & 334 & 285 & 232 \\
(\$ millions) & 5.00 & 2783 & 3343 & 2849 & 2321 \\
& 15.00 & 8350 & 10029 & 8547 & 6962 \\
& 45.00 & 25049 & 30088 & 25641 & 20887 \\
& 75.00 & 41748 & 50147 & 42735 & 34812 \\
\hline Customer average & 0.50 & 26 & 32 & 27 & 22 \\
(\$/customer) & 5.00 & 265 & 318 & 271 & 221 \\
& 15.00 & 794 & 953 & 812 & 662 \\
& 45.00 & 2381 & 2860 & 2437 & 1985 \\
& 75.00 & 3968 & 4767 & 4062 & 3309 \\
\hline
\end{tabular}

Interruption costs range drawn from Woo et al. [35]

Were the Florida electric grid to have performed commensurate with regions devoid of AMI deployment, the state could have expected 112 million additional hours of customer interruptions due to Hurricane Irma. We use a range of interruption cost estimates from Woo et al. [35]. At \$ 15 per customer interruption hour, the benefits from avoiding these additional interruption costs across the state of Florida approach $\$ 1.7$ billion. This total value estimate scales costs linearly with time and accounts interrupted as our data does not indicate how long any given interruption was sustained by an individual customer. If the hourly interruption cost is instead assumed to be the lowest value $(\$ 0.50)$ or highest value $(\$ 75)$, the benefits enjoyed from interruptions not sustained is estimated at $\$ 56$ million or $\$ 8.4$ billion respectively. The benefits already realized through the deployment of AMI, amount to $\$ 160$ per customer account when an interruption hour costs $\$ 15$. The low and high estimates for these benefits are $\$ 5$ and $\$ 798$ respectively.

With the second counterfactual $\left(C F_{1}\right)$ we assess how much better the system could have performed if additional opportunities were pursued. The central finding from comparing actual events with $C F_{1}$ is that 92 million interruption hours could be avoided through realization of additional AMI deployment opportunities in Florida. Moderately valued (\$ 15/customer-hour), this improvement in performance would generate an additional $\$ 1.4$ billion in benefits for stakeholders and an average of $\$ 132$ of benefits for each customer account.

The third counterfactual $\left(C F_{M}\right)$ estimates the performance of the distribution grid under the assumption of a uniform distribution of AMI penetration at the observed state-level 
Table 3. Comparison of actual and counterfactual outcomes

\begin{tabular}{lrrrrr}
\hline & Hourly Cost $(\$)$ & Actual & Actual- $C F_{0}$ & Actual- $C F_{M}$ & Actual- $C F_{1}$ \\
\hline Total interruption hours & & 557 & -112 & -13 & 92 \\
Florida SAIDI (Hours in 9.2017) & & 52.9 & -10.6 & -1.3 & 8.7 \\
\hline Total Interruption Costs & 0.50 & 278 & -56 & -7 & 46 \\
\$ millions) & 5.00 & 2783 & -560 & -66 & 462 \\
& 15.00 & 8350 & -1680 & -197 & 1387 \\
& 45.00 & 25049 & -5039 & -592 & 4162 \\
& 75.00 & 41748 & -8399 & -987 & 6936 \\
\hline Customer Average & 0.50 & 26 & -5 & -1 & 4 \\
(\$/customer) & 5.00 & 265 & -53 & -6 & 44 \\
& 15.00 & 794 & -160 & -19 & 132 \\
& 45.00 & 2381 & -479 & -56 & 396 \\
& 75.00 & 3968 & -798 & -94 & 659 \\
\hline Interruption costs range drawn from Woo et al. [35] & & & & \\
\hline
\end{tabular}

average $(57.4 \%)$. Estimates from $C F_{M}$ suggest that actual performance exceeded expectations associated with an even distribution of AMI penetration across the state by 13.2 million interruption hours. This difference is valued around \$ 197 million total, or \$ 19 per customer account. These estimates should be considered conservative as they assume only residential customers were impacted and that interruption costs scale linearly with time and number of accounts impacted. Furthermore, these values entail only interruption costs and do not address the cost of physical damages to the distribution system that must be repaired.

\section{Robustness Checks}

\subsection{Alternative Specifications}

The resilience of electric distribution grids is highly dependent upon network topology. Network topology data is regarded as proprietary and generally unavailable due to competitive or national security concerns. The reduced form estimation techniques, presented in the preceding section, allow for abstraction from matters of graph theory and compare the performance of grid segments (such as counties) with varying levels of weather stress and interoperability investment as indicated by AMI penetration.

Fundamentally, some segments of the electric distribution grid may be stronger in the face of wind stress than others. One might hypothesize that the built environment served by the distribution grid entails important variation in inherent resilience as a function of local household income or population density. Wealthier neighborhoods may have a relatively resilient built environment and density could correlate with the presence of large multifamily dwellings served by more robust connections to the electric grid. On the other hand, denser areas are also home to more customer accounts, implying greater numbers locally at risk. While much of this unobserved heterogeneity is absorbed into our fixed effects, 
the robustness of our findings is evaluated through the exploration of alternative model specifications that include additional explanatory variables. The following specification in Eq. (9) substitutes population density or median household income for AMI penetration, replacing $x_{2 i}$ without changing the functional form of the model.

$$
E\left[y_{i t} \mid \theta_{i}, x_{i t}\right]=\theta_{i} \exp \left(\beta_{1} x_{1 i t}+\beta_{2} x_{1 i t} x_{2 i}+\varepsilon_{i t}\right)
$$

Table 4 compares the results obtained from the core model specification and several alternatives at the utility-county level. Models (2) through (4) in Table 4 and Table 5 replace AMI share with sample normalized measures of population density, median household income, and new building share, respectively. The coefficient on the interaction of squared wind speed and population density, unlike that of AMI share, is greater than unity, suggesting density is associated with higher expectations of sustained interruptions. For each standard deviation increase in population density, the impact of a standard wind shock, measured in expected sustained interruptions, rises by $1.1 \%$. The interaction term in specification (3) indicates that a standard deviation increase in median household income leads to a $4.4 \%$ fall in expected interruptions per hour for a standard wind shock. Specification (4) suggests that there is no statistically significant difference in the expectation of interruptions for grid segments with different shares of new construction.

Table 4. Alternative regression model specifications (county-utility)

\begin{tabular}{|c|c|c|c|c|c|c|c|c|c|c|}
\hline Dependent Variable: $\Delta$ Interruptions & (1) & (2) & (3) & (4) & (5) & (6) & (7) & (8) & (9) & (10) \\
\hline Squared Wind Speed $\left(W^{2}\right)$ & $\begin{array}{l}1.588^{* * *} \\
(0.0000)\end{array}$ & $\begin{array}{l}1.475^{* * *} \\
(0.0000)\end{array}$ & $\begin{array}{l}1.542^{* * *} \\
(0.0000)\end{array}$ & $\begin{array}{l}1.532^{* * *} \\
(0.0000)\end{array}$ & $\begin{array}{l}1.591^{* * *} \\
(0.0000)\end{array}$ & $\begin{array}{l}1.613^{* * *} \\
(0.0000)\end{array}$ & $\begin{array}{l}1.621^{* * *} \\
(0.0000)\end{array}$ & $\begin{array}{l}1.623^{* * *} \\
(0.0000)\end{array}$ & $\begin{array}{l}1.647^{* * *} \\
(0.0000)\end{array}$ & $\begin{array}{l}1.499^{* * *} \\
(0.0000)\end{array}$ \\
\hline$W^{2} \times$ AMI-Share & $\begin{array}{c}0.905^{*} \\
(0.0120)\end{array}$ & & & & $\begin{array}{c}0.904 \\
(0.0721)\end{array}$ & $\begin{array}{c}0.920^{*} \\
(0.0494)\end{array}$ & $\begin{array}{c}0.905^{*} \\
(0.0190)\end{array}$ & $\begin{array}{l}0.863^{* *} \\
(0.0015)\end{array}$ & $\begin{array}{c}0.888^{*} \\
(0.0232)\end{array}$ & $\begin{array}{c}1.082 \\
(0.4796)\end{array}$ \\
\hline$W^{2} \times$ Population Density & & $\begin{array}{c}1.011 \\
(0.0588)\end{array}$ & & & $\begin{array}{c}0.999 \\
(0.9493)\end{array}$ & & & $\begin{array}{c}0.991 \\
(0.1762)\end{array}$ & & \\
\hline$W^{2} \times$ Median Household Income & & & $\begin{array}{l}0.956^{* *} \\
(0.0025)\end{array}$ & & & $\begin{array}{l}0.964^{* *} \\
(0.0037)\end{array}$ & & & $\begin{array}{c}0.921^{*} \\
(0.0211)\end{array}$ & \\
\hline$W^{2} \times$ New Building Share (Since 2000) & & & & $\begin{array}{c}0.900 \\
(0.5745)\end{array}$ & & & $\begin{array}{c}0.911 \\
(0.6218)\end{array}$ & & & $\begin{array}{c}1.405^{*} \\
(0.0473)\end{array}$ \\
\hline$W^{2} \times$ Population Density $\times$ AMI-Share & & & & & & & & $\begin{array}{c}1.037 \\
(0.3914)\end{array}$ & & \\
\hline$W^{2} \times$ Median Household Income $\times$ AMI-Share & & & & & & & & & $\begin{array}{c}1.069 \\
(0.1826)\end{array}$ & \\
\hline$W^{2} \times$ New Building Share $($ Since 2000) $\times$ AMI-Share & & & & & & & & & & $\begin{array}{c}0.395^{*} \\
(0.0486)\end{array}$ \\
\hline Observations & 144065 & 144065 & 144065 & 144065 & 144065 & 144065 & 144065 & 144065 & 144065 & 144,065 \\
\hline$B I C$ & $4.744 \mathrm{e}+07$ & $4.764 \mathrm{e}+07$ & $4.747 \mathrm{e}+07$ & $4.768 \mathrm{e}+07$ & $4.744 \mathrm{e}+07$ & $4.729 \mathrm{e}+07$ & $4.743 e+07$ & $4.739 \mathrm{e}+07$ & $4.726 \mathrm{e}+07$ & $4.728 \mathrm{e}+07$ \\
\hline
\end{tabular}

Specifications (5) through (7) enable the comparison of the size of effect expected from the shift of zero to 100 percent AMI share with that of a standard deviation increase in each of the three other interaction terms. While AMI share remains significant and close to 0.9 only the median household income interaction in specification (6) remains significant, though the size of the effect is diminished as the coefficient approaches one. Specifications (8) through (10) include a triple interaction between wind speed, AMI share, and the competing covariates. Only the triple interaction in specification (10) is significant, indicating that the resilience of relatively new construction coupled with AMI may be most capable 
of resisting sustained interruptions. However, in the absence of AMI deployment, increasing shares of new construction are associated with a higher expected value of sustained interruptions.

As a further robustness check the analysis presented in Table 4 is also conducted at the county-level and presented in Table 5. The interaction term for population density in specification (2) becomes even less significant when the analysis is conducted for the smaller county-level data set. The same is true for the new building share interaction term in specification (10). Otherwise, the pattern of coefficient sign and significance remains consistent across the two data sets.

Table 5. Alternative regression model specifications (county)

\begin{tabular}{|c|c|c|c|c|c|c|c|c|c|c|}
\hline Dependent Variable: $\Delta$ Interruptions & (1) & (2) & (3) & (4) & (5) & (6) & (7) & (8) & (9) & (10) \\
\hline Squared Wind Speed $\left(W^{2}\right)$ & $\begin{array}{l}1.595^{* * *} \\
(0.0000)\end{array}$ & $\begin{array}{l}1.481^{* * *} \\
(0.0000)\end{array}$ & $\begin{array}{l}1.546^{* * *} \\
(0.0000)\end{array}$ & $\begin{array}{l}1.534^{* * *} \\
(0.0000)\end{array}$ & $\begin{array}{l}1.604^{* * *} \\
(0.0000)\end{array}$ & $\begin{array}{l}1.619^{* * *} \\
(0.0000)\end{array}$ & $\begin{array}{l}1.625^{* * *} \\
(0.0000)\end{array}$ & $\begin{array}{l}1.638^{* * *} \\
(0.0000)\end{array}$ & $\begin{array}{l}1.651^{* * *} \\
(0.0000)\end{array}$ & $\begin{array}{l}1.502^{* * *} \\
(0.0000)\end{array}$ \\
\hline$W^{2} \times$ AMI-Share & $\begin{array}{c}0.904^{*} \\
(0.0213)\end{array}$ & & & & $\begin{array}{c}0.900 \\
(0.0874)\end{array}$ & $\begin{array}{c}0.919 \\
(0.0640)\end{array}$ & $\begin{array}{c}0.904^{*} \\
(0.0301)\end{array}$ & $\begin{array}{l}0.858^{* *} \\
(0.0084)\end{array}$ & $\begin{array}{c}0.889^{*} \\
(0.0464)\end{array}$ & $\begin{array}{c}1.082 \\
(0.4991)\end{array}$ \\
\hline$W^{2} \times$ Population Density & & $\begin{array}{c}1.010 \\
(0.1449)\end{array}$ & & & $\begin{array}{c}0.998 \\
(0.8487)\end{array}$ & & & $\begin{array}{c}0.989 \\
(0.2248)\end{array}$ & & \\
\hline$W^{2} \times$ Median Household Income & & & $\begin{array}{c}0.957^{* *} \\
(0.0097)\end{array}$ & & & $\begin{array}{c}0.964^{*} \\
(0.0138)\end{array}$ & & & $\begin{array}{c}0.924 \\
(0.0814)\end{array}$ & \\
\hline$W^{2} \times$ New Building Share (Since 2000) & & & & $\begin{array}{c}0.909 \\
(0.6167)\end{array}$ & & & $\begin{array}{c}0.919 \\
(0.6589)\end{array}$ & & & $\begin{array}{c}1.425 \\
(0.1226)\end{array}$ \\
\hline$W^{2} \times$ Population Density $\times$ AMI-Share & & & & & & & & $\begin{array}{c}1.038 \\
(0.3964)\end{array}$ & & \\
\hline$W^{2} \times$ Median Household Income $\times$ AMI-Share & & & & & & & & & $\begin{array}{c}1.065 \\
(0.3003)\end{array}$ & \\
\hline$W^{2} \times$ New Building Share $($ Since 2000) $\times$ AMI-Share & & & & & & & & & & $\begin{array}{c}0.390 \\
(0.0762)\end{array}$ \\
\hline Observations & 47904 & 47904 & 47904 & 47904 & 47904 & 47904 & 47904 & 47904 & 47904 & 47904 \\
\hline$B I C$ & $4.405 e+07$ & $4.426 \mathrm{e}+07$ & $4.409 \mathrm{e}+07$ & $4.429 \mathrm{e}+07$ & $4.405 \mathrm{e}+07$ & $4.391 \mathrm{e}+07$ & $4.404 \mathrm{e}+07$ & $4.399 \mathrm{e}+07$ & $4.388 \mathrm{e}+07$ & $4.389 \mathrm{e}+07$ \\
\hline
\end{tabular}




\subsection{Nonlinearity}

A series of tests were conducted to examine the potential for nonlinearity in the conditional expectation of service interruptions. We model the conditional expectation of the mean of service interruptions as an exponential function of a linear combination of the regressors, including wind speed and an interaction of wind speed and AMI share. The linear functional form of the main interaction may be misspecified if AMI share modulates the outage-effects of wind in a more complex manner, and this potential for nonlinear complexity was examined with a Ramsey RESET test [58]. The RESET test results indicate the presence of nonlinearity in the core regression for both the county and county-utility regressions, and both the Akaike and Bayesian information criteria (BIC) indicate a preference for specifications including higher order terms.

Although interpreting regression coefficients with higher-order interactions becomes increasingly complicated, the point estimates of the coefficients for the main interaction in this model remain qualitatively stable even as higher order terms are progressively introduced. Whereas the coefficient on the linear interaction of wind speed and the AMI-share interoperability proxy drops from around 0.9 to 0.7 with the inclusion of squared fitted values in the modified regression, it then remains stable around the latter value as cubic, quartic, and quantic specifications are evaluated. In all higher-order specifications the linear interaction term is less than one and statistically significant. The falling coefficient value lends additional evidence to our claim that our core regression specification is conservative and should be taken as a lower bound estimate of the modulating effects investments in smart grid interoperability will have on expected outages during severe weather events. Regression results for the specifications with higher-order interactions are presented in the supplementary materials, tables A2 and A3.

\subsection{Alternative Weather Data}

In response to hurricane-induced outages at the meteorological towers in Florida, we obtained alternative satellite-based hourly wind data from ERA5 dataset produced by the European Centre for Medium-Range Weather Forecasts. The core regression analysis was then conducted at the county level using metrics adapted from the ERA5 data, as well as a hybrid time series of wind speed constructed from meteorological tower data when available, and satellite data when many local towers suffer outages due to the hurricane. Fig. 12 presents the regression results from the alternative wind speed metrics. Whereas all three metrics capture the direct relationship between wind speed and the expected number of outages, the remote sensed and hybrid data appears insufficient to estimate with precision the coefficients on the interaction terms. 


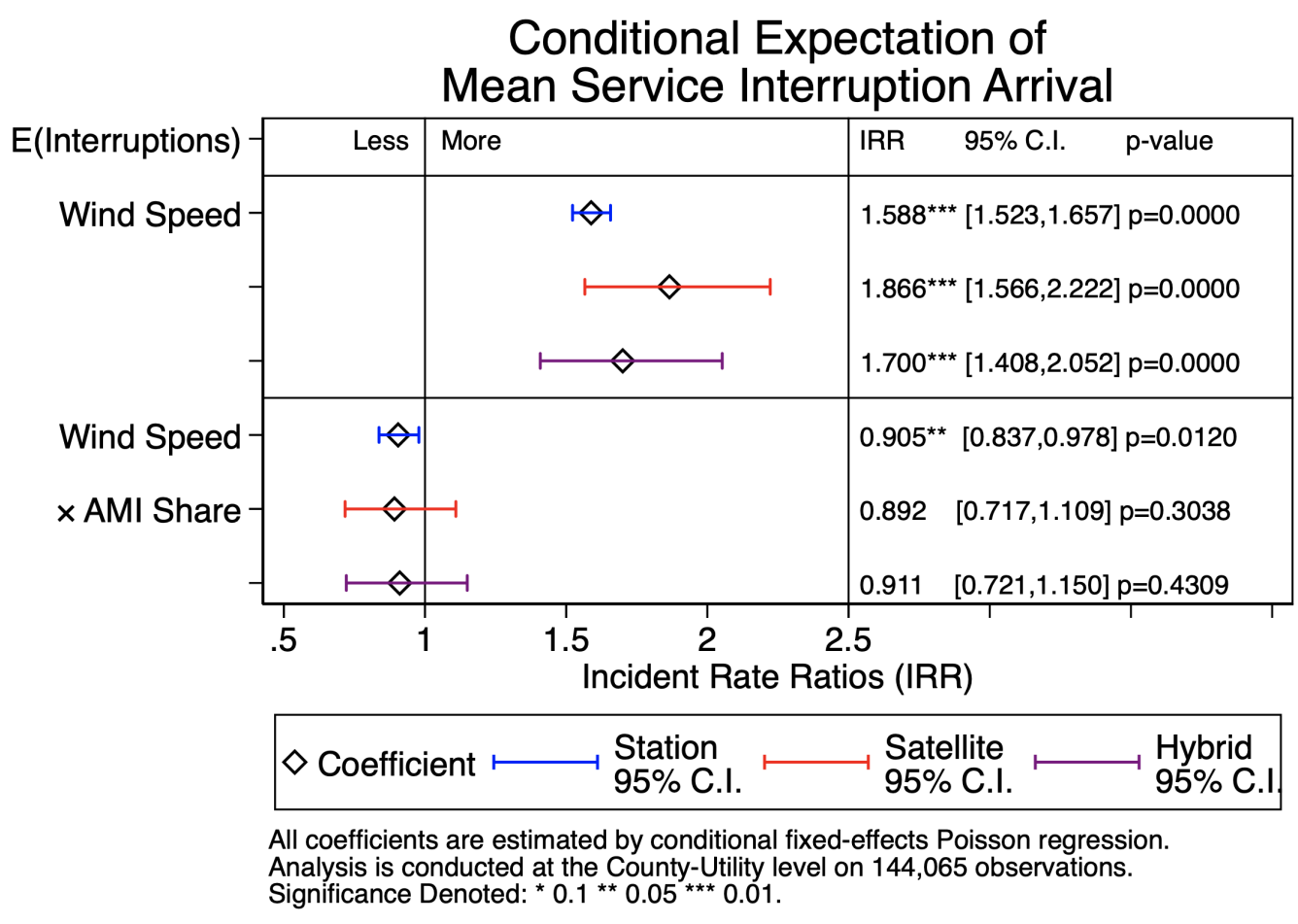

Fig. 12. Regression results with alternative wind speed metrics

\subsection{Impact of Weather Station Outages on Counterfactual Estimates}

Hurricane Irma caused outages at many of the weather stations in Florida responsible for producing the official local wind speed data. This means that many stations reported missing or zero values for wind speed in periods where the true value was higher. The zero values are incorporated into the synthetic wind speed data used for the primary analysis in this manuscript. As a result, the true value of wind speed incident on the grid is likely higher than reported for some hours.

Fig. 13 presents the actual and mean counterfactual interruptions series for MiamiDade County overlaid with the synthetic squared wind speed values for that county. Early on the $10^{\text {th }}$ of September 2017, weather station outages begin to impact the synthetic wind speed calculations. For this county, the station outages appear coincidently with the period of peak customer interruptions. We argue that the measurement error due to station outages impacts performance counterfactuals in a predictable manner and lends further support to our claim that the estimates produced in this study are conservative in nature, representing a lower bound on the resilience benefits from AMI penetration. This section discusses how our counterfactual estimates of sustained interruptions would change if we could obtain true wind speed data rather than the synthetic observed data.

We are interested in the gap between the actual and counterfactual estimate of interruptions accruing in any given hour as these values can be integrated to determine how much 


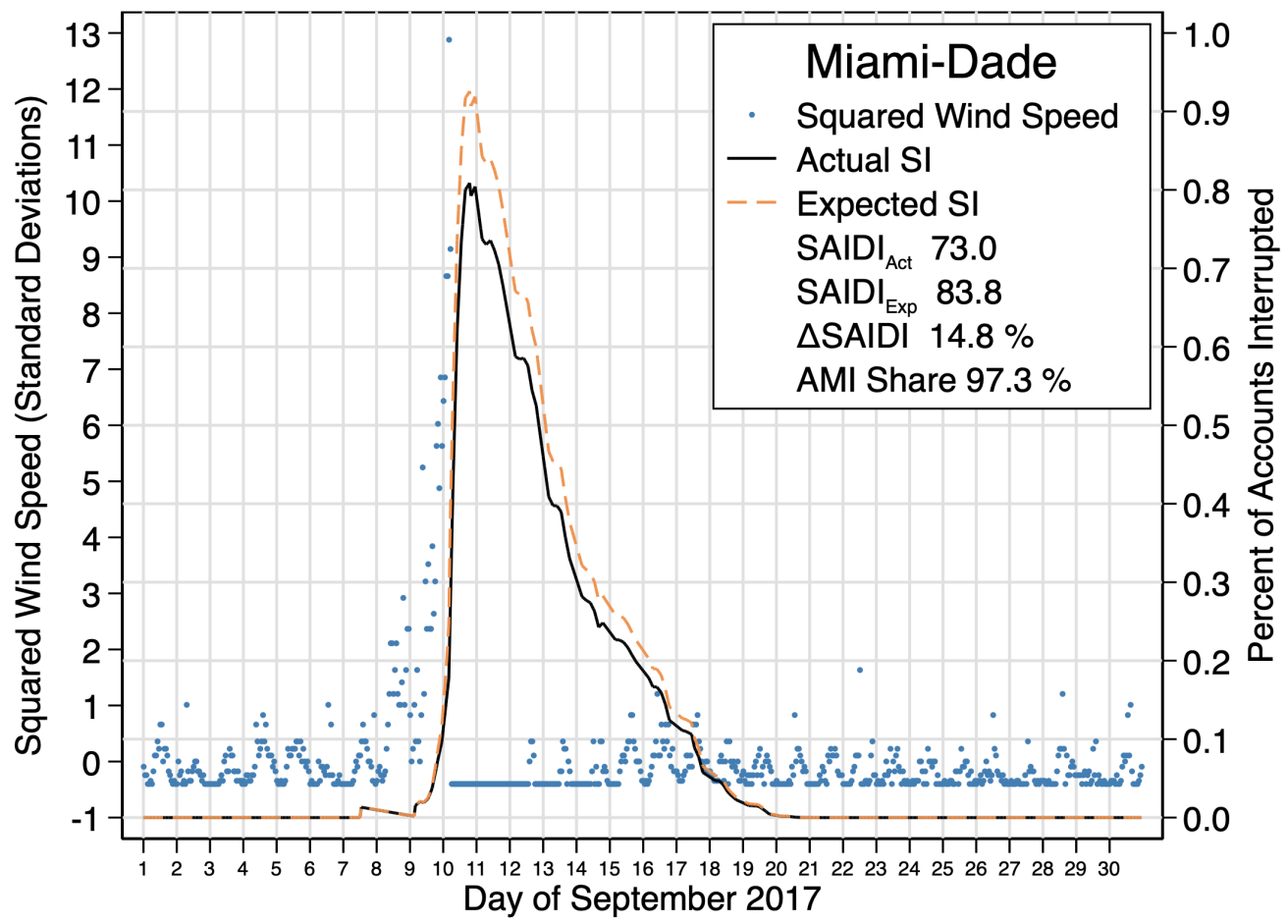

Fig. 13. Wind speeds and sustained interruptions in Miami-Dade County

better or worse system performance could have been with alternative levels of AMI. Let this difference be denoted $I_{i t}^{G a p}=I_{i t}^{C F}-I_{i t}^{A}$, where $I_{i t}^{C F}$ is the counterfactual estimate of interruptions in county $i$ and hour $t$, and $I_{i t}^{A}$ is the count of interruptions actually observed in our data. A positive $I_{i t}^{G a p}$ indicates that a county beat the expectations associated with the given counterfactual.

The expected impact of the weather station outages on our counterfactual exercise is investigated using a simple comparative statics approach. Let $W_{i t}$ denote the wind stress encountered by region $i$ in time $t$. Effectively, we wish to determine the sign of the expression found in Eq. 10 for two distinct cases.

$$
\begin{aligned}
\frac{\delta I_{i t}^{G a p}}{\delta W_{i t}} & \equiv \frac{\delta\left(I_{i t}^{C F}-I_{i t}^{A}\right)}{\delta W_{i t}} \\
I_{i t}^{C F} & =\left(I_{i t}^{A}\right)\left(R_{i t}^{G_{i}}\right) \\
\frac{\delta I_{i t}^{G a p}}{\delta W_{i t}} & \equiv\left(\frac{\delta I_{i t}^{A}}{\delta W_{i t}}\right)\left(R_{i t}^{G_{i}}-1\right)+\left(\frac{\delta R_{i t}}{\delta W_{i t}}\right)\left(I_{i t}^{A}\right)\left(G_{i}\right)\left(R_{i t}\right)^{\left(G_{i}-1\right)}
\end{aligned}
$$




\section{Case I: High-Interoperability County}

In Case I, $M_{i}>\widehat{M}$ implying $G_{i}$ is positive and less than one. In this case, we expect interruptions to be higher in the counterfactual scenario than they are in actuality. If the county performed commensurate with counties that have the average level of AMI, fewer interruptions would be handled within the momentary window, implying a higher rate at which interruptions are sustained.

Equation (10) is evaluated using the core findings of the paper. First, the two partial derivatives of $I_{i t}^{A}$ and $R_{i t}$ with respect to $W_{i t}$ are both positive. Actual interruptions are increasing in wind speed. The ratio of expected interruptions between the low AMI and high AMI cases is also increasing in wind speed. The sign on the second factor of the first term on the right-hand-side of Eq. (10) is known to be positive as $R_{i t} \geq 1$ and $0<G_{i}<1$. Actual interruptions are non-negative. By assumption, $G_{i}$ is positive in this case. Finally, $\left(R_{i t}\right)^{\left(G_{i}-1\right)}$ is a positive number taken to a negative power, which is thus positive as well.

$$
\begin{aligned}
& \frac{\delta I_{i t}^{\text {Gap }}}{\delta W_{i t}} \equiv \underbrace{\left(\frac{\delta I_{i t}^{A}}{\delta W_{i t}}\right)}_{\oplus} \underbrace{\left(R_{i t}^{G_{i}}-1\right)}_{\oplus}+\underbrace{\left(\frac{\delta R_{i t}}{\delta W_{i t}}\right)}_{\oplus} \underbrace{\left(I_{i t}^{A}\right)}_{\oplus} \underbrace{\left(G_{i}\right)}_{\oplus} \underbrace{\left(R_{i t}\right)^{\left(G_{i}-1\right)}}_{\oplus} \\
& \frac{\delta I_{i t}^{\text {Gap }}}{\delta W_{i t}}>0 \text { for } M_{i}>\widehat{M} \Longrightarrow I_{i t}^{\text {Gap }}>0
\end{aligned}
$$

The effect of a marginal change in the wind speed employed in the estimation of our counterfactuals can now be determined for the high AMI penetration scenario. For counties with high AMI penetration, employing more accurate (higher) wind speed values would lead to the estimation of a larger gap between the number of interruptions actually observed and the counterfactual scenario. As wind speeds used in this study are synthesized from the non-negative values observed at operational stations, weather station outages which led to the reporting of wind speeds of zero only impacts the synthetic values unidirectionally. Weather station outages due to high winds imply that the synthetic values employed are less than what would be obtained in the absence of such outages. In other words, the estimates of the resilience benefits enjoyed in these counties are lower bounds of the true value. Intuitively, the discrepancy between expected performance in the high and low AMI setting grows with the degree of wind insult incident on the distribution system.

\section{Case II: Low-Interoperability County}

In Case $2, M_{i}<\widehat{M}$ implying $G_{i}$ is negative and greater than -1 . In this case, we expect interruptions to be lower in the counterfactual case than they are in actuality. If the county performed commensurate with counties that have a greater level of AMI, more interruptions would be handled within the momentary window, implying a lower rate at which 
interruptions would be sustained. Again, Eq. (10) is evaluated using the core findings of the paper.

$$
\begin{aligned}
& \frac{\delta I_{i t}^{\text {Gap }}}{\delta W_{i t}} \equiv \underbrace{\left(\frac{\delta I_{i t}^{A}}{\delta W_{i t}}\right)}_{\oplus} \underbrace{\left(R_{i t}^{G_{i}}-1\right)}_{\ominus}+\underbrace{\left(\frac{\delta R_{i t}}{\delta W_{i t}}\right)}_{\oplus} \underbrace{\left(I_{i t}^{A}\right)}_{\oplus} \underbrace{\left(G_{i}\right)}_{\ominus} \underbrace{\left(R_{i t}\right)^{\left(G_{i}-1\right)}}_{\oplus} \\
& \frac{\delta I_{i t}^{\text {Gap }}}{\delta W_{i t}}<0 \text { for } M_{i}<\widehat{M} \Longrightarrow I_{i t}^{\text {Gap }}<0
\end{aligned}
$$

The gap between the counterfactual and actual interruptions is negative for low AMI counties. The use of more accurate (higher) wind speeds would make the gap more negative, once again, indicating that the estimates generated using the outage-afflicted weather data will tend to undercount the resilience benefits associated with an increase in AMI deployment.

\subsection{Alternative Interruption Cost Estimates}

As a further robustness check on the impact analysis produced by our counterfactual exercise, we employ the Interruption Cost Estimate (ICE) calculator [59] developed by Lawrence Berkeley National Laboratory and Nexant, Inc to value the additional 10.6 hours of interruption that we would expect for the average customer account under $C F_{0}$ relative to actuality. As interruption costs vary extensively across end use sector, we obtain counts of each customer type in the Florida electricity system from the Florida Public Service Commission [60]. Table 6 presents the ICE calculator results for the difference in interruption costs between the observed and $C F_{0}$ scenario, using the baseline assumptions for Florida. If each customer in Florida experienced an average of 10.6 additional hours of interruption, the total costs to Florida could be as high as $\$ 14.96$ billion. This number is higher than our other estimates due to the outsized impact of interruptions on commercial and industrial (C\&I) customers. The value estimates produced by the ICE calculator is additional evidence that our valuation of the benefits associated with AMI deployment and follow-on investment is conservative.

\begin{tabular}{|c|c|c|c|c|c|}
\hline Sector & \# of Customers & Cost Per Event & Cost Per Avg kW & Cost Per Unserved kWh & Total Cost \\
\hline Residential & 9398000 & 23.94 & 15.20 & 1.43 & 224965000 \\
\hline Small C\&I & 1053391 & 6592.87 & 3824.74 & 359.13 & 6944875000 \\
\hline Medium and Large C\&I & 267609 & 29095.94 & 598.87 & 56.23 & 7786334000 \\
\hline Total & 10719000 & 1395.30 & 504.89 & 47.41 & 14956175000 \\
\hline \multicolumn{6}{|c|}{$\begin{array}{l}\text { SOURCE: Values produced using the ICE Calculator, found at https://icecalculator.com/interruption-cost } \\
\text { NOTE: Customer counts are for December 31, } 2017 \text { and are drawn from "Statistics of the Florida Electric Utility Industry" } \\
\text { Florida Public Service Commission http://wwww.floridapsc.com/Files/PDF/Publications/Reports/Electricgas/Statistics/2017.pdf } \\
\text { Results presented incorporate default settings for Florida with a SAIDI equal to } 639 \text { minutes (SAIDI } C F_{0} \text { - SAIDI Actual), } \\
\text { and a system average interruption frequency index (SAIFI) of } 1.0 \text {. }\end{array}$} \\
\hline
\end{tabular}

Table 6. ICE calculator results (Actual - $C F_{0}$ ) 


\section{Conclusion}

Our reduced form analytic approach entails several advantages over the modeling approaches typically used in this space. First, the prescriptive nature of highly specified models narrows the applicability of results to explicit deterministic relationships. Second, the data requirements of highly specified models can be onerous-especially with respect to actual grid topology — and demand a level of detail often not available for the entire area of study. While a highly specified model would require topological detail with respect to distribution network structure, customer service interruptions, wind stress, and interoperability investments, a reduced form approach complements the existing literature by effectively characterizing broad trends in distribution system performance and balances tradeoffs between the scope and depth of analysis.

The speed with which utilities can integrate new data-intensive strategies into their operations, harnessing interoperability to drive performance improvements, will in part, reflect the success of regulated firms in demonstrating the prudence of these options to create and protect public value streams. This manuscript employs public data resources in one such demonstration. AMI, a leading indicator of follow-on investments in the smart grid, does not prevent the initial component outage that leads to a service interruption. Instead, automated systems for network protection, outage management, and restoration enable utilities to maintain service continuity through network reconfiguration even when confronted with a major hurricane. The expected number of interruption hours sustained during Hurricane Irma was relatively lower for regions of the Florida distribution grid that made such interoperability enhancing investments. The realized benefits to Florida's electric grid performance with greater interoperability is valued close to $\$ 1.7$ billion for a single large event.

\section{Acknowledgments}

The authors would like to thank Dr. David Butry, Dr. David Webb, and Dr. Kenneth Harrison for providing thoughtful comments on drafts of this manuscript. We are grateful for helpful conversations and feedback from Dr. Jennifer Helgeson, Dr. Judith Mitrani-

Reiser, Dr. Stanley Gilbert, Dr. Joshua Kneifel and Anand Kandaswamy. Any errors or omissions remain the responsibility of the authors.

\section{References}

[1] IEEE (2003) Ieee guide for electric power distribution reliability indices. IEEE Std 1366 .

[2] Taft J (2017) Electric grid resilience and reliability for grid architecture. Pacific Northwest National Laboratory Available at https://gridarchitecture.pnnl.gov/media/ advanced/Electric_Grid_Resilience_and_Reliability.pdf. 
[3] Greer C, Wollman DA, Prochaska DE, Boynton PA, Mazer JA, Nguyen CT, FitzPatrick GJ, Nelson TL, Koepke GH, Hefner Jr AR, et al. (2014) Nist framework and roadmap for smart grid interoperability standards, release 3.0 (NIST),

[4] Obama B (2013) Presidential policy directive/ppd-21: Critical infrastructure security and resilience, february 12, 2013.

[5] US Department of Energy (2016) Advanced metering infrastructure and customer systems, results from the smart grid investment grant program (Department of Energy, US),

[6] North American Electricity Reliability Corporation (2018) Hurricane irma event analysis report (North American Electricity Reliability Corporation), Report.

[7] Reed DA, Kapur KC, Christie RD (2009) Methodology for assessing the resilience of networked infrastructure. IEEE Systems Journal 3(2):174-180.

[8] Powell MD, Reinhold TA (2007) Tropical cyclone destructive potential by integrated kinetic energy. Bulletin of the American Meteorological Society 88(4):513-526.

[9] Grilo A, Jardim-Goncalves R (2010) Value proposition on interoperability of bim and collaborative working environments. Automation in construction 19(5):522-530.

[10] Loukis EN, Charalabidis YK (2013) An empirical investigation of information systems interoperability business value in european firms. Computers in Industry 64(4):412-420.

[11] Walker J, Pan E, Johnston D, Adler-Milstein J, Bates DW, Middleton B (2005) The value of health care information exchange and interoperability: There is a business case to be made for spending money on a fully standardized nationwide system. Health affairs 24(Suppl1):W5-10.

[12] US Department of Energy (2011) Recovery act selections for smart grid investment grant awards by state (U.S. Department of Energy), Report.

[13] Cangialosi JP, Latto AS, Berg R (2018) Hurricane irma (al112017). National Hurricane Center Tropical Cyclone Report .

[14] Rodriguez R (2017) Hurricane irma damage could be as high as \$65 billion. Miami Herald Available at http://www.miamiherald.com/news/weather/hurricane/ article174153646.html.

[15] Stein P, Berman M, Lowery W (2017) Hurricane irma makes second landfall in florida and will roar up the state's gulf coast. The Washington Post Available at https://www.washingtonpost.com/news/post-nation/wp/2017/09/ 10/hurricane-irma-makes-landfall-in-florida-keys-targets-gulf-coast/?utm_term= $.45 \mathrm{cb} 7 \mathrm{~b} 7905 \mathrm{bf}$.

[16] Hines P, Apt J, Talukdar S (2008) Trends in the history of large blackouts in the united states. Power and Energy Society General Meeting-Conversion and Delivery of Electrical Energy in the 21st Century, 2008 IEEE (IEEE), , pp 1-8.

[17] Wang Y, Chen C, Wang J, Baldick R (2016) Research on resilience of power systems under natural disasters - a review. IEEE Trans Power Syst 31(2):1604-1613.

[18] Florida Public Service Commission (2018) Review of florida's electric utility hurricane preparedness and restoration actions (Florida Public Service Commission), Re- 
port.

[19] Bureau of Labor Statistics (2018) Occupational employment and wages, may 2019, 49-9051 electrical power-line installers and repairers (Bureau of Labor Statistics), Available at https://www.bls.gov/oes/current/oes499051.htm.

[20] Bureau of Labor Statistics (2018) Occupational employment and wages, may 2019, 17-2071 electrical engineers (Bureau of Labor Statistics), Available at https://www. bls.gov/oes/current/oes172071.htm.

[21] Folga S, McLamore M, Talaber L, Tompkins A (2016) National electricity emergency response capabilities (U.S. Department of Energy, Office of Energy Policy and Systems Analysis), Report.

[22] Hodge T, Lee A (2017) Hurricane irma cut power to nearly two-thirds of florida's electricity customers (Energy Information Administration), Report. Available at https: //www.eia.gov/todayinenergy/detail.php?id=32992.

[23] Czajkowski J, Done J (2014) As the wind blows? understanding hurricane damages at the local level through a case study analysis. Weather, climate, and society 6(2):202217.

[24] Guikema SD, Nateghi R, Quiring SM, Staid A, Reilly AC, Gao M (2014) Predicting hurricane power outages to support storm response planning. IEEE Access 2:13641373.

[25] Davidson RA, Liu H, Sarpong IK, Sparks P, Rosowsky DV (2003) Electric power distribution system performance in carolina hurricanes. Natural Hazards Review 4(1):36-45.

[26] Winkler J, Duenas-Osorio L, Stein R, Subramanian D (2010) Performance assessment of topologically diverse power systems subjected to hurricane events. Reliability Engineering \& System Safety 95(4):323-336.

[27] Li G, Zhang P, Luh PB, Li W, Bie Z, Serna C, Zhao Z (2014) Risk analysis for distribution systems in the northeast us under wind storms. IEEE Transactions on Power Systems 29(2):889-898.

[28] Nateghi R, Guikema S, Quiring SM (2014) Power outage estimation for tropical cyclones: Improved accuracy with simpler models. Risk analysis 34(6):1069-1078.

[29] Miller K (2017) Measuring hurricanes hard when gauges go down, as they did during irma.

[30] Shepard D (1968) A two-dimensional interpolation function for irregularly-spaced data. Proceedings of the 1968 23rd ACM national conference (ACM), , pp 517-524.

[31] Abraham J, Strapp JW, Fogarty C, Wolde M (2004) Extratropical transition of hurricane michael: An aircraft investigation. Bulletin of the American Meteorological Society 85(9):1323-1340.

[32] Dominianni C, Lane K, Johnson S, Ito K, Matte T (2018) Health impacts of citywide and localized power outages in new york city. Environmental health perspectives 126(6):067003-067003.

[33] Rose A, Oladosu G, Liao S (2007) Business interruption impacts of a terrorist attack on the electric power system of los angeles: customer resilience to a total blackout. 
Risk Analysis: An International Journal 27(3):513-531.

[34] Lawton L, Sullivan M, Van Liere K, Katz A, Eto J (2003) A framework and review of customer outage costs: Integration and analysis of electric utility outage cost surveys (U.S. Department of Energy),

[35] Woo CK, Ho T, Shiu A, Cheng Y, Horowitz I, Wang J (2014) Residential outage cost estimation: Hong kong. Energy policy 72:204-210.

[36] Caves DW, Herriges JA, Windle RJ (1992) The cost of electric power interruptions in the industrial sector: estimates derived from interruptible service programs. Land Economics :49-61.

[37] Baik S, Davis AL, Morgan MG (2018) Assessing the cost of large-scale power outages to residential customers. Risk Analysis 38(2):283-296.

[38] McNulty S, Solutions E (2001) The cost of power disturbances to industrial and digital economy companies. EPRI IntelliGrid Initiative, Ref no 1006274.

[39] LaCommare KH, Eto JH (2006) Cost of power interruptions to electricity consumers in the united states (us). Energy 31(12):1845-1855.

[40] The Council of Economic Advisers (2013) Economic benefits of increasing electric grid resilience to weather outages. Washington, DC: Executive Office of the President

[41] Reed DA (2008) Electric utility distribution analysis for extreme winds. Journal of Wind Engineering and Industrial Aerodynamics 96(1):123-140.

[42] Liu H, Davidson RA, Rosowsky DV, Stedinger JR (2005) Negative binomial regression of electric power outages in hurricanes. Journal of infrastructure systems 11(4):258-267.

[43] Wei Y, Ji C, Galvan F, Couvillon S, Orellana G, Momoh J (2012) Non-stationary random process for large-scale failure and recovery of power distributions. arXiv preprint arXiv: 12024720 .

[44] Han SR, Guikema SD, Quiring SM, Lee KH, Rosowsky D, Davidson RA (2009) Estimating the spatial distribution of power outages during hurricanes in the gulf coast region. Reliability Engineering \& System Safety 94(2):199-210.

[45] Han S, Guikema SD, Quiring SM (2009) Improving the predictive accuracy of hurricane power outage forecasts using generalized additive models. Risk Analysis: An International Journal 29(10):1443-1453.

[46] Rose NL (1990) Profitability and product quality: Economic determinants of airline safety performance. Journal of Political Economy 98(5, Part 1):944-964.

[47] Keeler TE (1994) Highway safety, economic behavior, and driving environment. The American Economic Review 84(3):684-693.

[48] Silva JS, Tenreyro S (2006) The log of gravity. The Review of Economics and statistics 88(4):641-658.

[49] Fally T (2015) Structural gravity and fixed effects. Journal of International Economics 97(1):76-85.

[50] De Sousa J (2012) The currency union effect on trade is decreasing over time. Economics Letters 117(3):917-920. 
[51] Wooldridge JM (1999) Quasi-likelihood methods for count data. Handbook of Applied Econometrics Volume 2: Microeconomics :352-406.

[52] Hall BH, Griliches Z, Hausman JA (1984) Patents and r\&d: Is there a lag? (National Bureau of Economic Research),

[53] Blundell R, Griffith R, Reenen JV (1995) Dynamic count data models of technological innovation. The Economic Journal 105(429):333-344.

[54] Wooldridge JM (1999) Distribution-free estimation of some nonlinear panel data models. Journal of Econometrics 90(1):77-97.

[55] Burger M, Van Oort F, Linders GJ (2009) On the specification of the gravity model of trade: zeros, excess zeros and zero-inflated estimation. Spatial Economic Analysis 4(2):167-190.

[56] Wooldridge JM (2010) Econometric analysis of cross section and panel data (MIT press), .

[57] Bertanha M, Moser P (2016) Spatial errors in count data regressions. Journal of Econometric Methods 5(1):49-69.

[58] Ramsey JB (1969) Tests for specification errors in classical linear least-squares regression analysis. Journal of the Royal Statistical Society: Series B (Methodological) 31(2):350-371.

[59] Sullivan M, Collins MT, Schellenberg J, Larsen PH (2018) Estimating power system interruption costs: A guidebook for electric utilities (Lawrence Berkeley National Laboratory),

[60] Florida Public Service Commission (2018) Statistics of the florida electric utility industry (Florida Public Service Commission), Report.

\section{Appendix A: Supplemental Materials}

All the code and data inputs necessary to replicate the findings presented in this document can be obtained from the following URL. https://doi.org/10.18434/mds2-2359

\section{A.1 Covariate Balance of high and low AMI subsamples}

Table 7 presents evidence of the covariate balance between high AMI and low AMI subsamples harnessed in the calculation of counterfactuals. Table 7 presents the mean and standard errors of covariates for each subsample in columns (1) and (2). Column (3) presents the difference in sample means as well as the p-value of this difference in parentheses. The statistically significant difference in AMI share is an intentional outcome of the sample bifurcation. However, our county-level measures of median household income, land area, population, and population density all exhibit an insignificant difference between the mean values of each subsample. Variables are also generated containing the share of the built environment constructed since a given base year. The subsamples are not significantly different from each other with respect to these descriptors of the built environment served by the distribution grid. 
Table 7. Covariate Balance Table

\begin{tabular}{lccc}
\hline Variable & Low AMI & High AMI & Difference \\
\hline AMI-Share & 0.194 & 0.831 & $0.637 * * *$ \\
& $(0.181)$ & $(0.162)$ & $(0.000)$ \\
Median Household Income & 48083 & 49646 & 1563 \\
& $(8070)$ & $(10147)$ & $(0.486)$ \\
County Area & 758 & 829 & 71 \\
& $(377)$ & $(386)$ & $(0.457)$ \\
Population & 326664 & 304112 & -22551 \\
& $(406423)$ & $(554687)$ & $(0.848)$ \\
Population Density & 494 & 294 & -200 \\
& $(767)$ & $(375)$ & $(0.213)$ \\
New Building Share (Since 1940) & 0.968 & 0.975 & 0.007 \\
New Building Share (Since 1950) & $(0.021)$ & $(0.019)$ & $(0.152)$ \\
& 0.942 & 0.955 & 0.013 \\
New Building Share (Since 1960) & $(0.036)$ & $(0.030)$ & $(0.122)$ \\
& 0.884 & 0.904 & 0.019 \\
New Building Share (Since 1970) & 0.805 & 0.828 & 0.023 \\
& $(0.085)$ & $(0.077)$ & $(0.257)$ \\
New Building Share (Since 1980) & 0.640 & 0.667 & 0.027 \\
& $(0.114)$ & $(0.096)$ & $(0.316)$ \\
New Building Share (Since 1990) & 0.437 & 0.456 & 0.019 \\
New Building Share (Since 2000) & $(0.125)$ & $(0.094)$ & $(0.506)$ \\
Share of Buildings Built After 2014 & 0.249 & 0.251 & 0.002 \\
New Building Share (Since 2014) & $(0.105)$ & $(0.076)$ & $(0.942)$ \\
& 0.028 & 0.023 & -0.004 \\
Counties & $(0.029)$ & $(0.013)$ & $(0.471)$ \\
& 0.005 & 0.004 & -0.001 \\
NOTE: Values in parentheses are $p$-values for difference column. & $(0.006)$ & $(0.003)$ & $(0.284)$ \\
\hline
\end{tabular}




\section{A.2 Nonlinearity}

Tables 8 and 9 present the results obtained from higher order alternative specifications.

Table 8. Quadratic-Quintic Interactions with Wind and AMI-Share (County-Utility)

\begin{tabular}{lccccc}
\hline Dependent Variable: $\Delta$ Interruptions & $(1)$ & $(2)$ & $(3)$ & $(4)$ & $(5)$ \\
\hline \multirow{2}{*}{ Squared Wind Speed } & $1.588^{* * *}$ & $5.062^{* * *}$ & $5.050^{* * *}$ & $4.792^{* * *}$ & $4.801^{* * *}$ \\
& $(0.0000)$ & $(0.0000)$ & $(0.0000)$ & $(0.0000)$ & $(0.0000)$ \\
Squared Wind Speed $\times$ AMI-Share & $0.905^{*}$ & $0.736^{* * *}$ & $0.722^{* * *}$ & $0.734^{* * *}$ & $0.734^{* * *}$ \\
& $(0.0120)$ & $(0.0000)$ & $(0.0000)$ & $(0.0000)$ & $(0.0000)$ \\
Quadratic Fitted Values & & $0.914^{* * *}$ & $0.888^{* * *}$ & $0.815^{* * *}$ & $1.541^{*}$ \\
& & $(0.0000)$ & $(0.0000)$ & $(0.0000)$ & $(0.0227)$ \\
Cubic Fitted Values & & $1.001^{* * *}$ & $1.010^{*}$ & $0.913^{* *}$ \\
& & & $(0.0003)$ & $(0.0119)$ & $(0.0019)$ \\
Quartic Fitted Values & & & $1.000^{*}$ & $1.006^{* * *}$ \\
& & & & $(0.0327)$ & $(0.0006)$ \\
Quintic Fitted Values & & & & $1.000^{* * *}$ \\
& & & & & $(0.0003)$ \\
\hline Observations & 144065 & 144065 & 144065 & 144065 & 144065 \\
BIC & $4.744 \mathrm{e}+07$ & $3.875 \mathrm{e}+07$ & $3.846 \mathrm{e}+07$ & $3.831 \mathrm{e}+07$ & $3.786 \mathrm{e}+07$ \\
\hline Exponentiated coefficients. $p$-values in parentheses. ${ }^{*} p<0.05,{ }^{* *} p<0.01,{ }^{* * *} p<0.001$ \\
\hline
\end{tabular}


Table 9. Quadratic-Quintic Interactions with Wind and AMI-Share (County)

\begin{tabular}{lccccc}
\hline Dependent Variable: $\Delta$ Interruptions & $(1)$ & $(2)$ & $(3)$ & $(4)$ & $(5)$ \\
\hline Squared Wind Speed & $1.595^{* * *}$ & $6.291^{* * *}$ & $6.258^{* * *}$ & $5.802^{* * *}$ & $5.749^{* * *}$ \\
& $(0.0000)$ & $(0.0000)$ & $(0.0000)$ & $(0.0000)$ & $(0.0000)$ \\
Squared Wind Speed $\times$ AMI-Share & $0.904^{*}$ & $0.694^{* * *}$ & $0.691^{* * *}$ & $0.702^{* * *}$ & $0.705^{* * *}$ \\
& $(0.0213)$ & $(0.0000)$ & $(0.0000)$ & $(0.0000)$ & $(0.0000)$ \\
Quadratic Fitted Values & & $0.905^{* * *}$ & $0.891^{* * *}$ & $0.734^{* * *}$ & 1.292 \\
& & $(0.0000)$ & $(0.0000)$ & $(0.0000)$ & $(0.4542)$ \\
Cubic Fitted Values & & & 1.001 & $1.019^{* *}$ & 0.938 \\
& & & $(0.1346)$ & $(0.0015)$ & $(0.1883)$ \\
Quartic Fitted Values & & & & $1.000^{* *}$ & 1.004 \\
& & & & $(0.0017)$ & $(0.1152)$ \\
Quintic Fitted Values & & & & & 1.000 \\
& & & & & \\
\hline Observations & 47904 & 47904 & 47904 & 47904 & 47904 \\
BIC & $4.405 \mathrm{e}+07$ & $3.419 \mathrm{e}+07$ & $3.414 \mathrm{e}+07$ & $3.384 \mathrm{e}+07$ & $3.372 \mathrm{e}+07$ \\
\hline Exponentiated coefficients. $p$-values in parentheses. ${ }^{*} p<0.05,{ }^{* *} p<0.01,{ }^{* * *} p<0.001$ & & \\
\hline
\end{tabular}




\section{A.3 SAIDI Full Results}

Fig. 14 presents a measure of county-level distribution grid performance with the counties ordered by AMI penetration from high to low. Fig. 15 presents the same data ordered by the size of the performance differential. Our measure of performance is the gap between the expected counterfactual $\left(C F_{M}\right)$ SAIDI value and the actual SAIDI divided by the actual SAIDI value. This metric can be applied to answer the question of how well counties performed relative to expectations if AMI were deployed uniformly across Florida. Positive values for the relative performance metric indicate that actual interruptions were lower than would be expected with uniform AMI deployment. Negative values on the performance metric suggest that the county performed worse than it could have with the average penetration of AMI.

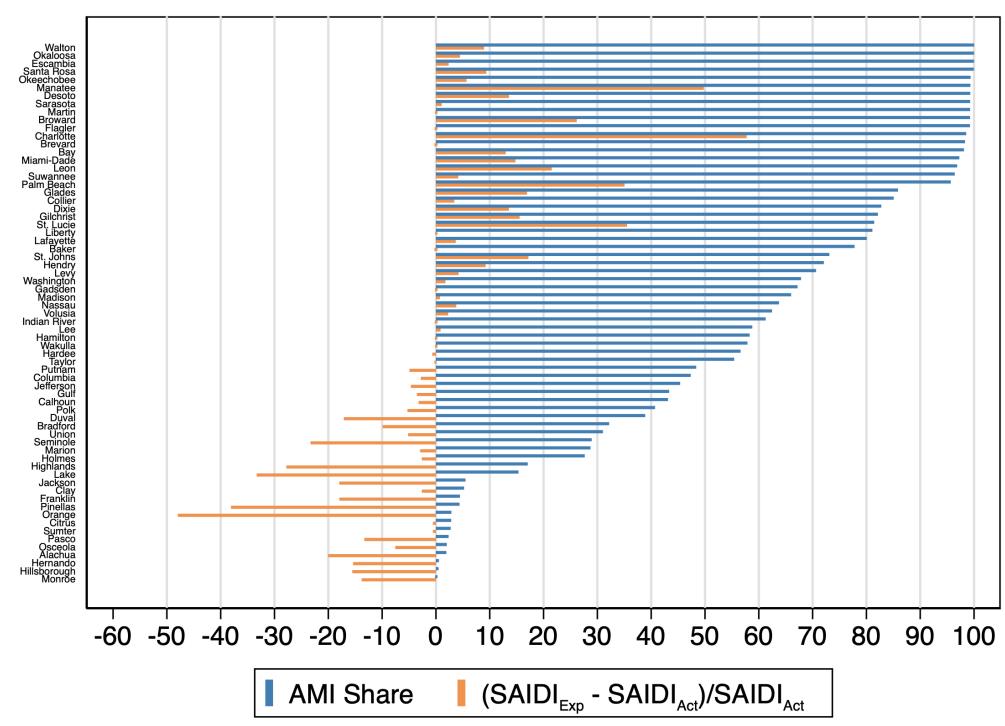

Fig. 14. SAIDI Performance and AMI Share 


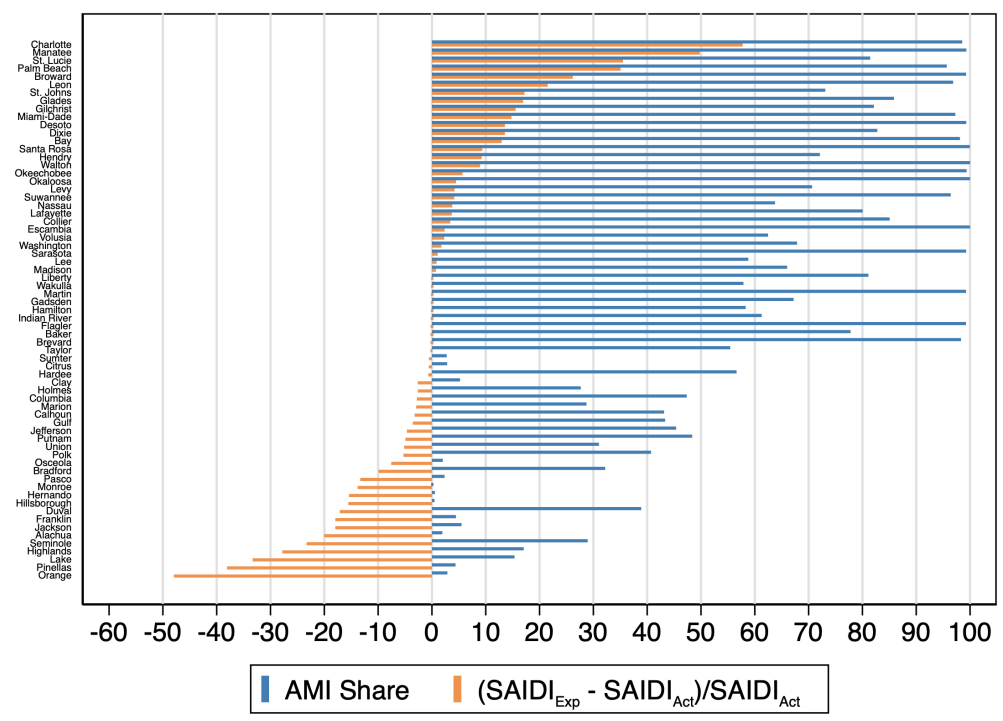

Fig. 15. SAIDI Performance and AMI Share 


\section{A.4 Pairwise Graphical Comparison of Select Counties}

Figures 16-18 present three pairwise comparisons of adjacent counties.

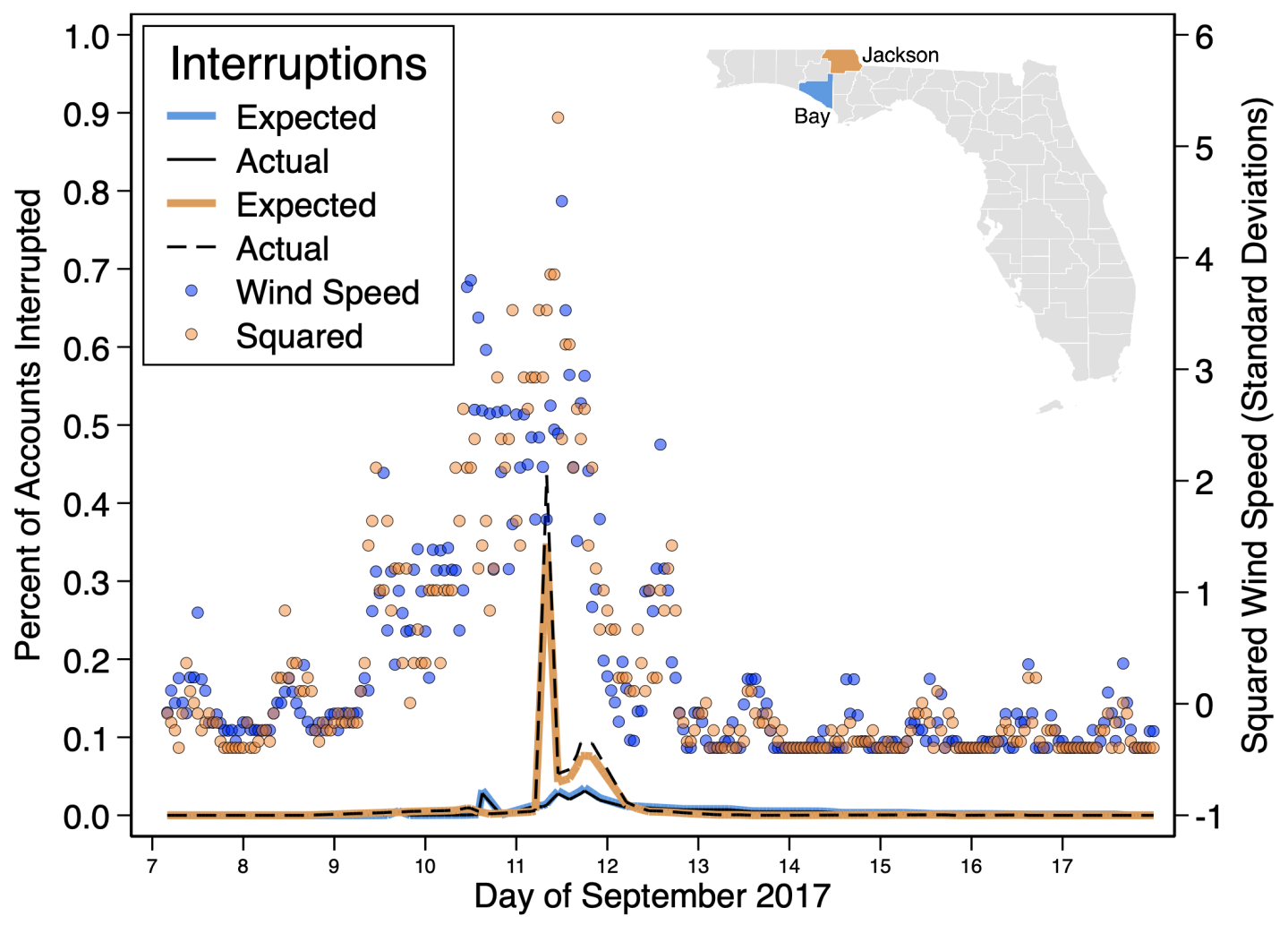

Fig. 16. Bay and Jackson 


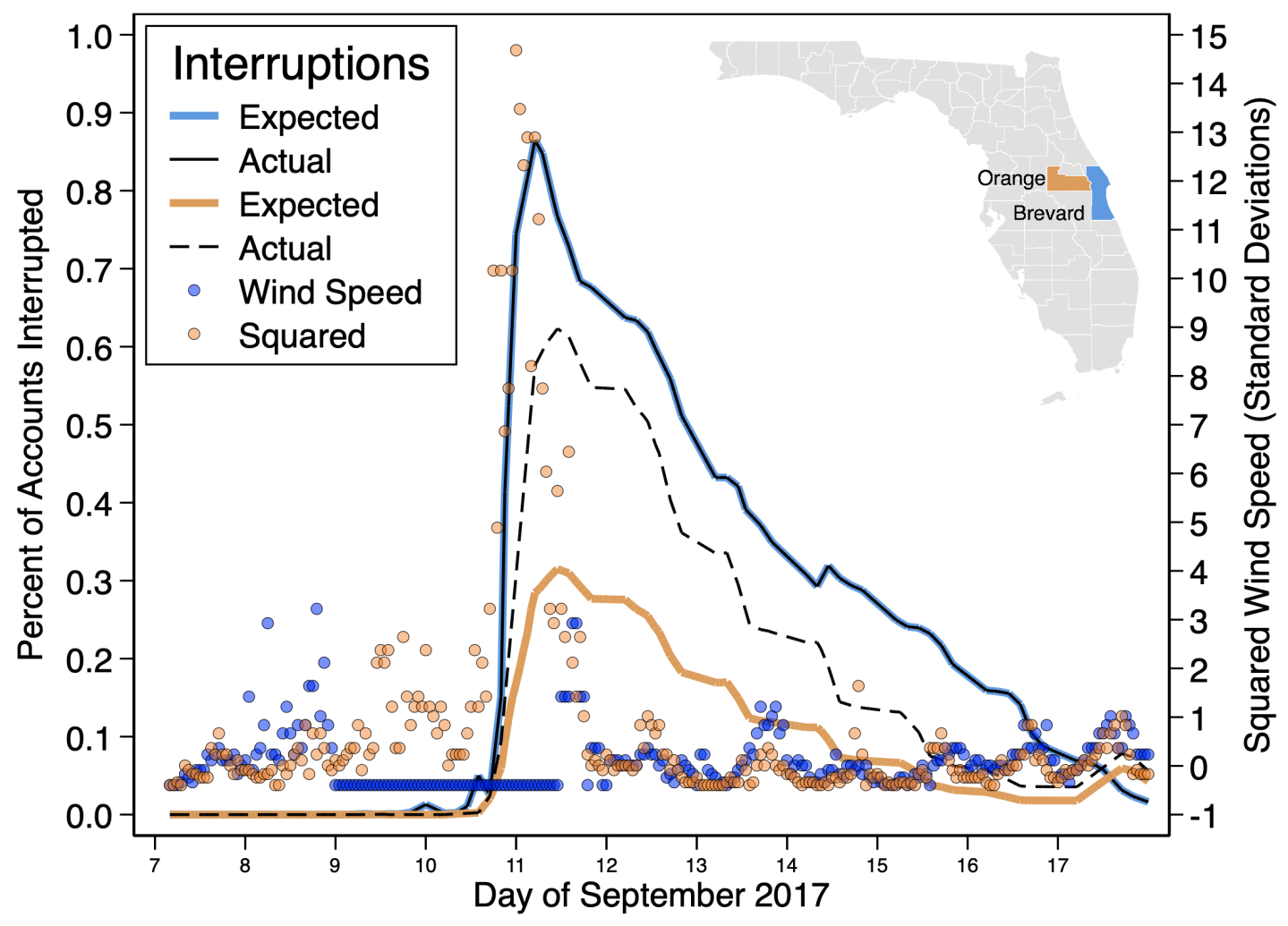

Fig. 17. Orange and Brevard 


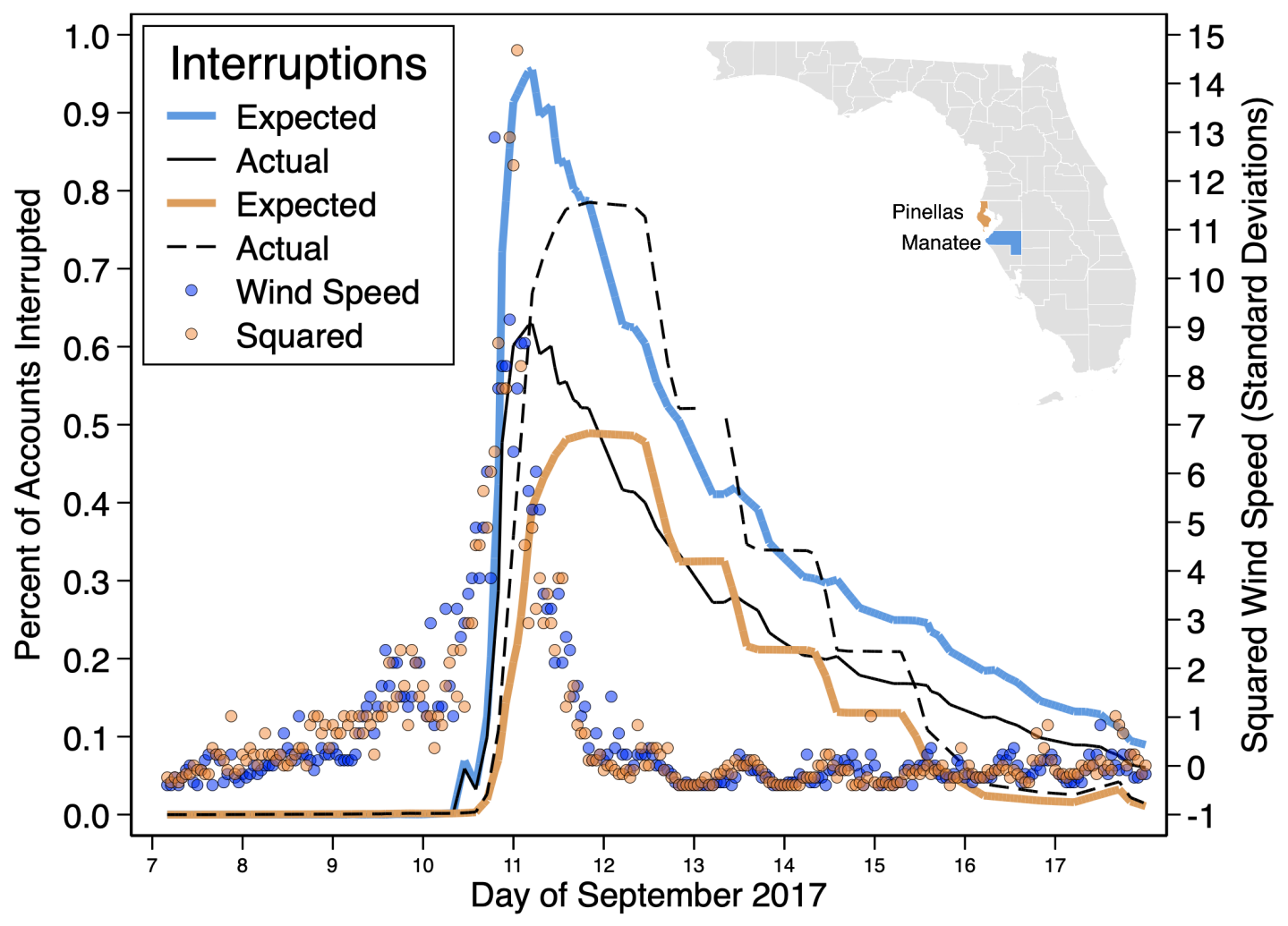

Fig. 18. Pinellas and Manatee 